\title{
Gluconate suppresses seizure activity in developing brains by inhibiting CLC-3 chloride channels
}

\author{
Zheng $\mathrm{Wu}^{1 \dagger}$, Qingwei Huo ${ }^{2,6 \dagger}$, Liang Ren ${ }^{3}$, Fengping Dong ${ }^{1}$, Mengyang Feng ${ }^{1}$, Yue Wang ${ }^{1}$, Yuting Bai', \\ Bernhard Lüscher ${ }^{1}$, Sheng-Tian Li ${ }^{4}$, Guan-Lei Wang ${ }^{5}$, Cheng Long ${ }^{2}$, Yun Wang ${ }^{3}$, Gangyi Wu ${ }^{1,2}$ and Gong Chen ${ }^{1 *}$ (D)
}

\begin{abstract}
Neonatal seizures are different from adult seizures, and many antiepileptic drugs that are effective in adults often fail to treat neonates. Here, we report that gluconate inhibits neonatal seizure by inhibiting CLC-3 chloride channels. We detect a voltage-dependent outward rectifying $\mathrm{Cl}^{-}$current mediated by $\mathrm{CLC}-3 \mathrm{Cl}^{-}$channels in early developing brains but not adult mouse brains. Blocking $\mathrm{CLC}-3 \mathrm{Cl}^{-}$channels by gluconate inhibits seizure activity both in neonatal brain slices and in neonatal animals with in vivo EEG recordings. Consistently, neonatal neurons of CLC-3 knockout mice lack the outward rectifying $\mathrm{Cl}^{-}$current and show reduced epileptiform activity upon stimulation. Mechanistically, we demonstrate that activation of $\mathrm{CLC}-3 \mathrm{Cl}^{-}$channels alters intracellular $\mathrm{Cl}^{-}$ homeostasis and enhances GABA excitatory activity. Our studies suggest that gluconate can suppress neonatal seizure activities through inhibiting $\mathrm{CLC}-3 \mathrm{Cl}^{-}$channels in developing brains.
\end{abstract}

Keywords: Neonatal seizure, Epilepsy, Gluconate, Anticonvulsant, CLC-3, Chloride channels, GABA

\section{Introduction}

The incidence of epilepsy is highest in the first year of life with a reported rate around 1.8-3.5/1000 live births in the United States [1]. Although many antiepileptic drugs (AEDs) have been developed for the treatment of adult epilepsy over the past several decades, neonatal seizures still lack safe and effective treatment $[2,3]$. In some cases, even after AED application, electroencephalographic (EEG) recordings still show ongoing cortical epileptic activity in neonates, which may impair cognitive development and later result in epilepsy $[2,4,5]$. Unfortunately, to date there have been few drugs that can effectively treat neonatal seizures, prompting an urgent need to search for new drugs.

Epileptic seizures are often caused by over-excitation of neural circuits. Because $\mathrm{GABA}_{\mathrm{A}}$ receptors $\left(\mathrm{GABA}_{\mathrm{A}}-\mathrm{Rs}\right)$ are the major inhibitory receptors in the adult brain, AEDs are often developed to increase $\mathrm{GABA}_{\mathrm{A}}$-Rs function, such

\footnotetext{
* Correspondence: gongchen@psu.edu; http://bio.psu.edu/directory/guc2 ${ }^{\dagger}$ Zheng Wu and Qingwei Huo contributed equally to this work.

${ }^{1}$ Department of Biology, Huck Institutes of Life Sciences, The Pennsylvania State University, University Park, PA 16802, USA

Full list of author information is available at the end of the article
}

as benzodiazepine and barbiturate drugs [6]. However, while $\mathrm{GABA}_{\mathrm{A}}$-Rs are mostly inhibitory in the adult brain, they can be excitatory in developing brains $[7,8]$. Therefore, many AEDs that boost GABA function are often ineffective in controlling neonatal seizures, and sometimes even exacerbate neonatal seizure activity $[9,10]$. Classically, GABA excitatory versus inhibitory function has been attributed to the regulation by $\mathrm{Cl}^{-}$co-transporters NKCC1 and $\mathrm{KCC} 2[8,11]$. A previous study suggested that NKCC1 might be a potential drug target for the treatment of neonatal seizures [12], but recent clinical trials in human infants found severe side effect of NKCC1 blocker bumetanide and limited effect in treating neonatal seizure [13]. Because GABAergic transmission plays an important role in brain development $[8,11]$, blocking NKCC1 may potentially alter normal brain functions $[14,15]$. Besides $\mathrm{Cl}^{-}$co-transporters, $\mathrm{Cl}^{-}$channels [16-18] and impermeant anions [19] also contribute to the regulation of $\mathrm{Cl}^{-}$ homeostasis and affect the epileptiform activity in the brain. Interestingly, the CLC-3 knockout mice show spontaneous generalized tonic-clonic seizures in adult animals, but not young animals (4-5 weeks) [20]. Another study reported a slight down-regulation of CLC-3c chloride 
channels during development [21]. It is unclear whether these two studies have any relationship. More broadly, whether $\mathrm{Cl}^{-}$channels are involved in neonatal epilepsy is largely unknown.

Here, we report that voltage-dependent CLC-3 $\mathrm{Cl}^{-}$ channels play an important role in neonatal epileptiform activity. We first demonstrated in cultured neurons that gluconate inhibited voltage-dependent $\mathrm{Cl}^{-}$currents and epileptiform activities. We then found in brain slices that CLC-3 $\mathrm{Cl}^{-}$channels mediated a large voltage-dependent outward rectifying $\mathrm{Cl}^{-}$current in neonatal but not in adult mouse brains. Gluconate effectively suppressed epileptiform activity in neonatal brain slices but had a lesser effect in adult brain slices. We further demonstrated with in vivo EEG recordings that gluconate was more effective in inhibiting seizure activity in neonatal animals than in adult animals. Finally, we demonstrated that activation of $\mathrm{CLC}-3 \mathrm{Cl}^{-}$channels during epileptiform activity significantly increased intracellular $\mathrm{Cl}^{-}$ concentration $\left(\left[\mathrm{Cl}^{-}\right]_{\mathrm{i}}\right)$ and enhanced GABA excitation, whereas knocking out or blocking $\mathrm{CLC}-3 \mathrm{Cl}^{-}$channels with gluconate reduced $\left[\mathrm{Cl}^{-}\right]_{\mathrm{i}}$ and suppressed over-excitation of GABA. Thus, gluconate inhibits neonatal seizure activity through blocking $\mathrm{CLC}-3 \mathrm{Cl}^{-}$channels.

\section{Results}

\section{Gluconate effectively inhibits epileptiform activity in cultured neurons}

The functional roles of cation channels such as $\mathrm{Na}^{+}, \mathrm{K}^{+}$, and $\mathrm{Ca}^{2+}$ channels in epilepsy have been well documented in previous studies [22-24], but the function of anion channels in epilepsy is not well understood. Here, we report a serendipitous finding of gluconate inhibition of both $\mathrm{Cl}^{-}$channels and epileptiform activity, leading to a new revelation of the relationship between $\mathrm{Cl}^{-}$channels and epilepsy. We initially investigated how external $\mathrm{Cl}^{-}$in bath solution regulates neuronal activity in cortical cultures. To our surprise, when we replaced only $20 \mathrm{mM} \mathrm{NaCl}$ with $20 \mathrm{mM}$ sodium gluconate (NaGluc, Sigma G9005) in the bath solution, which contained a total of $139 \mathrm{mM} \mathrm{Cl}^{-}$, the spontaneous burst activity was effectively blocked (Fig. 1a). This was an unexpected finding because a mere difference of $20 \mathrm{mM} \mathrm{Cl}^{-}$, from $139 \mathrm{mM}$ to $119 \mathrm{mM}$, is unlikely to explain why all burst activity had been inhibited. We therefore hypothesized that such strong inhibition could be caused by gluconate itself, rather than by the minor change of extracellular $\mathrm{Cl}^{-}$. To test this hypothesis, we examined the effect of gluconate on the robust epileptiform activity induced by a convulsant drug cyclothiazide (CTZ) [25]. Indeed, we found that CTZ-induced epileptiform activity was significantly blocked by application of $10 \mathrm{mM}$ NaGluc in the bath solution (Fig. 1b-c). Furthermore, we found that gluconate also significantly inhibited the epileptiform activities induced by kainic acid (KA) (Fig. 1d) and 4-AP (Fig. 1e). Together, these data indicate that NaGluc exerts a strong inhibitory effect on epileptiform burst activity in cultured neurons.

\section{Gluconate protects cultured neurons against KA-induced cell death}

Recurrent epileptic activity may induce cell death both in epileptic patients and animal models [26]. To evaluate whether the anti-epileptic effect of NaGluc might be neuroprotective, we employed kainic acid (KA) induced cell death model [25], and used the cytotoxicity kit (Life Technologies, L3224) to analyze the neuronal survival rate after KA treatment. In the control group, most neurons appeared to be healthy and stained by calcein (green, live cell marker) (Fig. 1f, left). After exposure to $10 \mu \mathrm{M}$ KA for $24 \mathrm{~h}$, most neurons were dead as shown by staining of cell death marker ethidium homodimer-1 (EthD-1, red) (Fig. 1f, middle left). Interestingly, co-application of $20 \mathrm{mM}$ NaGluc with KA greatly reduced neuronal death (Fig. 1f, middle right). As a control, neurons exposed to $20 \mathrm{mM} \mathrm{NaGluc}$ alone had no detriment to cell survival (Fig. 1f, right). Quantitative analysis showed a dose-dependent neuroprotective effect of NaGluc (Fig. 1g). These experiments suggest that gluconate protects cultured neurons against KA-induced excitotoxicity.

\section{Gluconate inhibits $\mathrm{Cl}^{-}$channels}

We next investigated why NaGluc can have such an inhibitory effect on epileptiform activity. Because gluconate ion is an organic anion used to replace $\mathrm{Cl}^{-}$, we investigated its potential effect on anion and cation channels. In the presence of NaGluc $(10 \mathrm{mM})$, we found no significant changes in $\mathrm{Na}^{+}, \mathrm{K}^{+}$and $\mathrm{Ca}^{2+}$ currents in neuronal cultures (Additional file 1: Figure S1A-F). Note that, gluconate might chelate $\mathrm{Ca}^{2+}$ in alkaline condition but not in physiological $\mathrm{pH}$ range (7.2-7.4). We found no effect of gluconate on $\mathrm{Ca}^{2+}$ currents in cell cultures or brain slices (Additional file 1: Figure S1G, H). Thus, it must be a mechanism other than $\mathrm{Ca}^{2+}$ current change underlying the gluconate inhibition of the burst activity. Indeed, we found that the voltage-dependent $\mathrm{Cl}^{-}$currents were significantly decreased in the presence of 10 mM NaGluc (Fig. 2a, b; control, $913 \pm 171$ pA; NaGluc, $499 \pm 89 \mathrm{pA} ; n=7 ; P<0.007$, paired Student's $t$-test; holding potential at $+90 \mathrm{mV}$ ). Thus, NaGluc may act as a $\mathrm{Cl}^{-}$channel blocker, which is consistent with previous report that gluconate can block $\mathrm{Cl}^{-}$channels in glioma cells [27]. Since NaGluc also inhibited epileptiform activity, we wondered whether these results indicated a potential link between $\mathrm{Cl}^{-}$channels and epileptiform activity. To test this hypothesis, we examined two widely used $\mathrm{Cl}^{-}$channel blockers, 5-Nitro-2-(3-phenylpropylamino) benzoic acid 


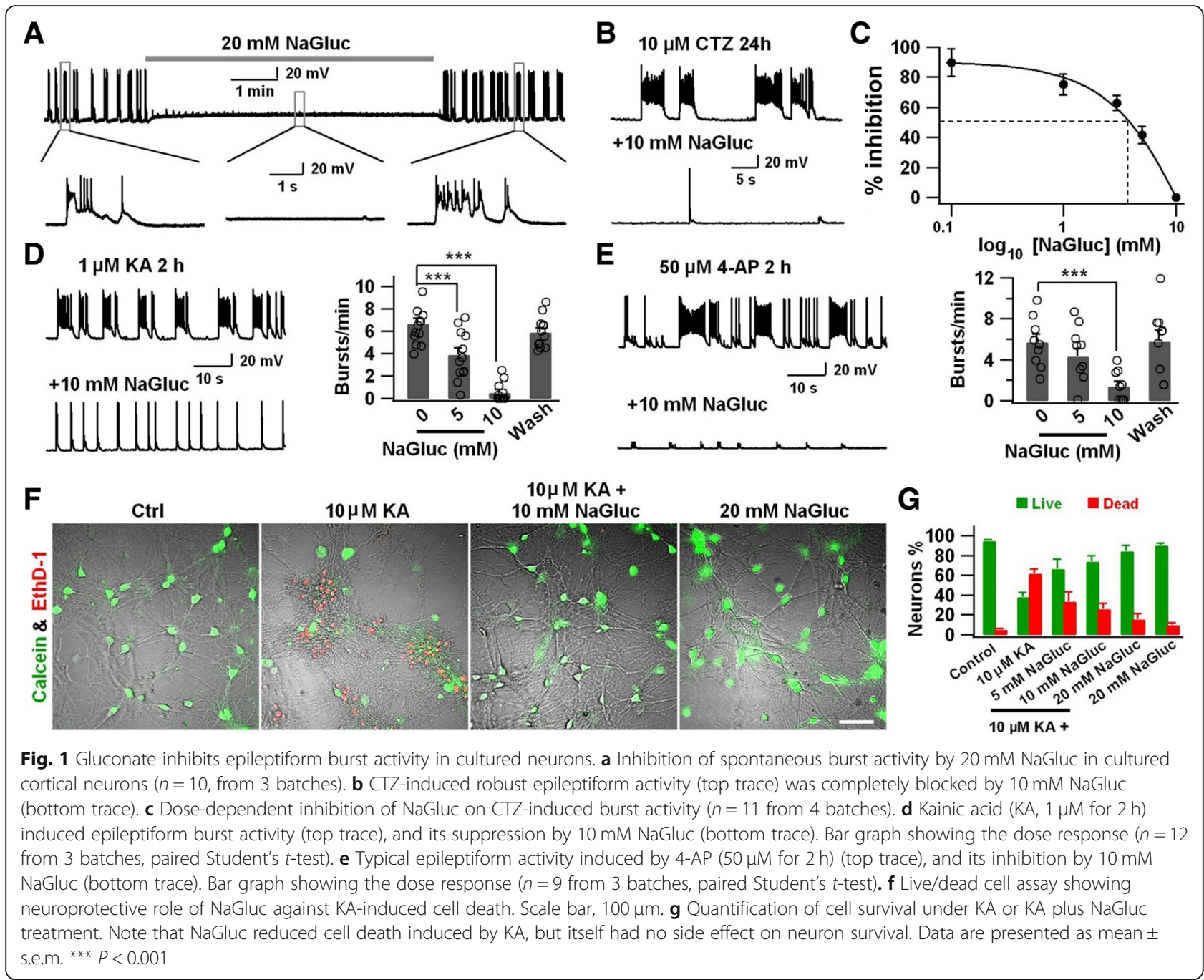

(NPPB) and 4,4'-Diisothiocyanato-2,2' -stilbenedisulfonic acid disodium salt (DIDS). As expected, both NPPB $(100 \mu \mathrm{M})$ and DIDS $(100 \mu \mathrm{M})$ suppressed $\mathrm{Cl}^{-}$currents in cultured neurons (Fig. 2c-f). Interestingly, they also inhibited the epileptiform activity induced by CTZ (Fig. 2g, h, $n=9$ ). Together, these results suggest that $\mathrm{Cl}^{-}$channels are closely linked to epileptiform activity.

Compared to other $\mathrm{Cl}^{-}$channel blockers such as NPPB and DIDS, gluconate has been widely used as a food additive or a drug additive approved by the FDA. Therefore, we decided to focus our study on gluconate in the rest of our experiments to further test whether gluconate can inhibit epileptiform activity in brain slices or live animals.

\section{Downregulation of $\mathrm{CLC}-3 \mathrm{Cl}^{-}$channels during brain development}

After the cell culture study, we further investigated the effect of gluconate on the $\mathrm{Cl}^{-}$currents in hippocampal slices. To isolate $\mathrm{Cl}^{-}$currents, the $\mathrm{Na}^{+}, \mathrm{K}^{+}$and $\mathrm{Ca}^{2+}$ cations in the bath solution were all replaced by impermeable cation $\mathrm{NMDG}^{+}$to reduce their potential effects. High $\mathrm{Cl}^{-}$concentration in the pipette solution $(140 \mathrm{mM}$ $\mathrm{Cl}^{-}$) was used for the $\mathrm{Cl}^{-}$current recording except where otherwise stated. Whole-cell patch-clamp recordings revealed a large voltage-dependent outward rectifying $\mathrm{Cl}^{-}$current $(3.3 \pm 0.3 \mathrm{nA})$ in the CA3 pyramidal neurons of neonatal mice (P8-12) (Fig. 3a, top left panel). Surprisingly, the $\mathrm{Cl}^{-}$current decreased significantly in the adult brains (P60-62) (Fig. 3a, b). Such dramatic downregulation of voltage-dependent outward rectifying $\mathrm{Cl}^{-}$current during brain development was unexpected. Importantly, application of NaGluc significantly inhibited the $\mathrm{Cl}^{-}$currents in neonatal hippocampal slices (Fig. 3c, d). The $\mathrm{IC}_{50}$ of NaGluc on the $\mathrm{Cl}^{-}$ currents in neonatal hippocampal neurons (P10-12) was about $8.6 \mathrm{mM}$ (Fig. 3d). To ensure that the large $\mathrm{Cl}^{-}$ current was not caused by the high $\mathrm{Cl}^{-}$concentration in the pipette solution, we recorded $\mathrm{Cl}^{-}$currents using 15 $\mathrm{mM} \mathrm{Cl} \mathrm{Cl}^{-}$in the pipette solution $(125 \mathrm{mM}$ acetate in 

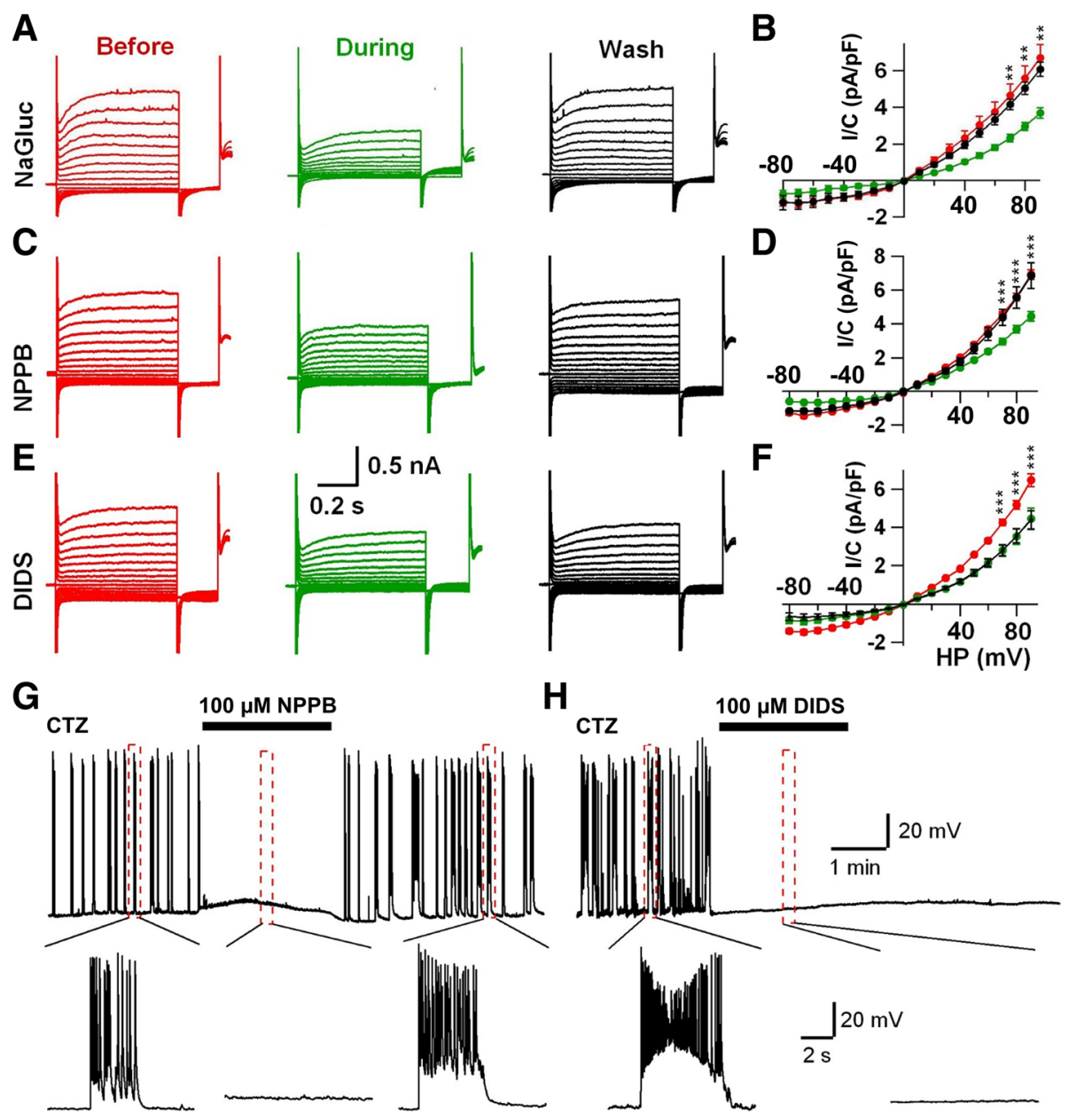

Fig. 2 Gluconate inhibits $\mathrm{Cl}^{-}$current in cultured neurons. a, b Typical $\mathrm{Cl}^{-}$currents recorded before (red), during $10 \mathrm{mM}$ NaGluc application (green), and wash out NaGluc (black). I-V curves showing a significant inhibition of NaGluc on the Cl- currents ( $n=7$ from 3 batches of cultures, paired Student's t-test). c-f NPPB and DIDS $(100 \mu \mathrm{M})$, two classical $\mathrm{Cl}^{-}$channel blockers, inhibited the $\mathrm{Cl}^{-}$currents in cultured neurons. $\mathbf{g}$, $\mathbf{h}$ Both NPPB $(\mathbf{g})$ and DIDS $(\mathbf{h})$ inhibited the epileptiform activity induced by CTZ. Data are presented as mean \pm s.e.m. ${ }^{* *} P<0.01,{ }^{* * *} P<0.001$

pipette solution), a concentration closer to physiological level, and found similar inhibition by NaGluc (Additional file 1: Figure S2). Thus, gluconate is an inhibitor of the voltage-dependent $\mathrm{Cl}^{-}$channels in neonatal brains.

We next investigated the molecular identity of the voltage-dependent $\mathrm{Cl}^{-}$currents. A previous study revealed a large $\mathrm{CLC}-3 \mathrm{Cl}^{-}$channel mediated outward rectifying current in hippocampal cultures [18]. Therefore, we investigated CLC-3 $\mathrm{Cl}^{-}$channels in the brains of both wildtype (WT) and $\mathrm{Clcn}^{-/-}$mice. Knockout of CLC-3 was confirmed by PCR and immunohistochemistry, which also showed significantly smaller body size compared to the WT littermates (Fig. 3e). Whole-cell recordings from WT hippocampal CA3 pyramidal neurons showed a large voltage-dependent outward rectifying $\mathrm{Cl}^{-}$ current in neonatal brain slices (Fig. 3f, WT, P8-12), similar to that reported previously in cultured hippocampal neurons [18]. However, in neonatal $\mathrm{Clcn3}^{-/-}$ mice (P8-12, before hippocampal degeneration) [20, 28], the large $\mathrm{Cl}^{-}$current was remarkably reduced (Fig. 3f, g; WT: $33.1 \pm 1.3 \mathrm{pA} / \mathrm{pF},+90 \mathrm{mV}, n=10$ vs CLC-3 KO: 9.0 $\pm 1.6 \mathrm{pA} / \mathrm{pF},+90 \mathrm{mV}, n=6 . P<0.001$, unpaired Student's $t$-test). Application of NaGluc to CLC-3 KO neurons had no further effect on the remaining small current (Fig. 3g). These results indicate that the $\mathrm{Cl}^{-}$current in neonatal CA3 pyramidal neurons is mainly mediated by CLC-3 chloride channels.

To more directly test the idea of NaGluc as an inhibitor of CLC-3 $\mathrm{Cl}^{-}$channels, we overexpressed CLC-3 $\mathrm{Cl}^{-}$ channels in HEK293T cells [29] and confirmed their expression with CLC-3 specific antibodies (Additional file 1: Figure S3A). Whole-cell recordings revealed large outward rectifying $\mathrm{Cl}^{-}$currents in CLC-3-transfected HEK293T cells $(1012 \pm 123 \mathrm{pA}, n=7)$, but not in EGFP-transfected control cells (Additional file 1: Figure S3B). Application of $20 \mathrm{mM}$ NaGluc significantly reduced the CLC-3 

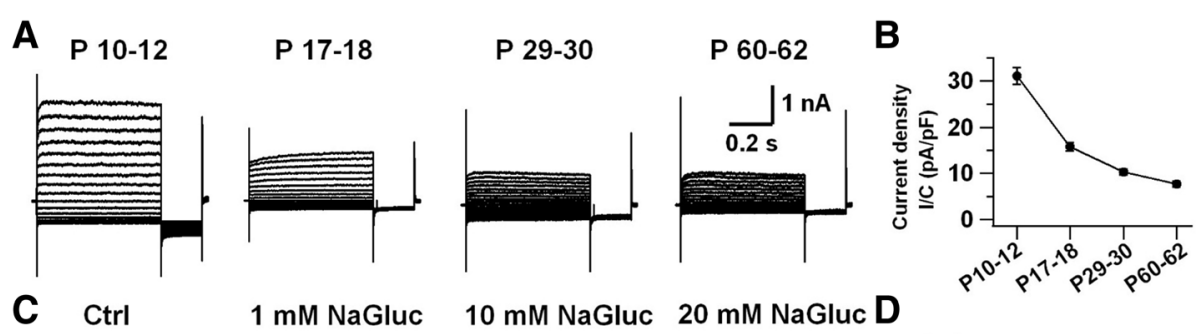

C Ctrl
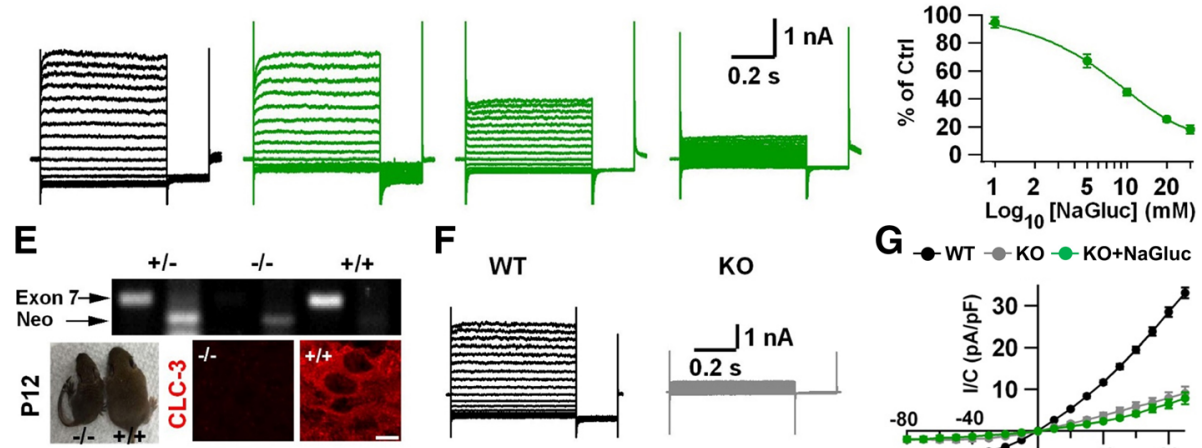

F wT

KO

G $\bullet-w T \rightarrow K O \rightarrow K O+N a G l u c$
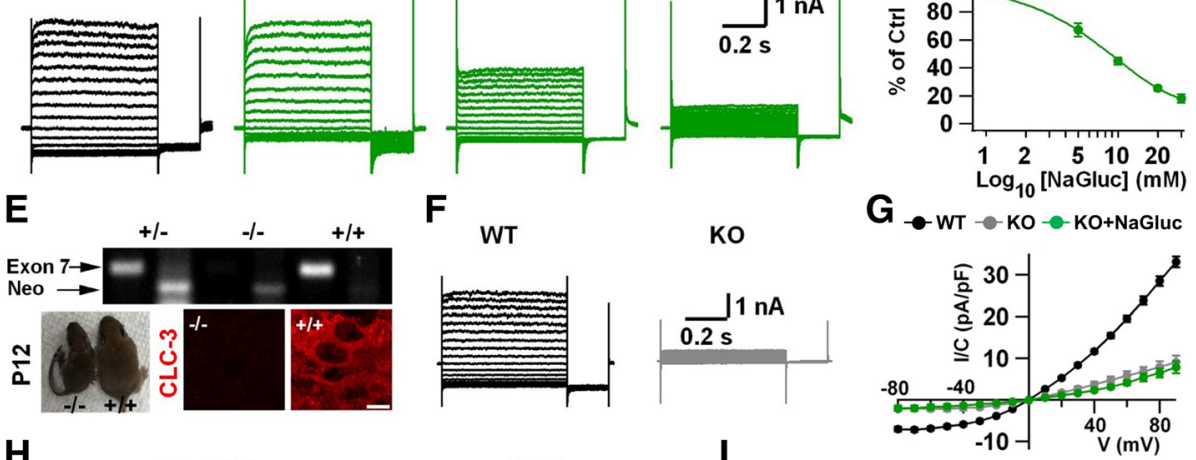

H
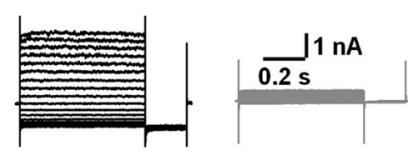

I
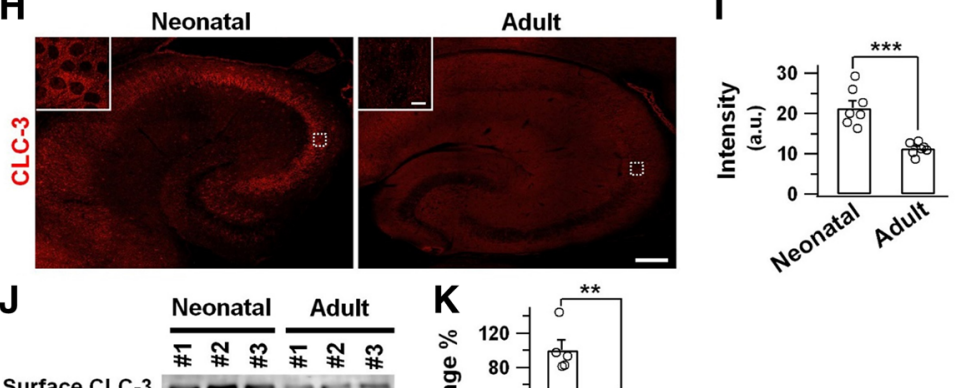

Surface CLC-3

$\mathrm{Na}^{+}-\mathrm{K}^{+}$ATPase $-\mathrm{CH}=\mathrm{N}$



Fig. 3 Developmental change of $\mathrm{CLC}-3 \mathrm{Cl}^{-}$channels in the mouse brain. a Representative traces of voltage-dependent $\mathrm{Cl}^{-}$currents recorded in CA3 pyramidal neurons at different ages of animals. $\mathbf{b}$ Quantified $\mathrm{Cl}^{-}$current density $(\mathrm{HP}=+90 \mathrm{mV}$ ) illustrating age-dependent decline during early brain development. c NaGluc inhibition of $\mathrm{Cl}^{-}$currents in WT neonatal neurons (P10-12). $\mathbf{d}$ Dose-response curve of $\mathrm{NaGluc}$ inhibition on $\mathrm{Cl}^{-}$ currents in hippocampal slices. e Characterization of CLC-3 knockout mice. PCR analysis confirmed a lack of the exon 7 of Clcn3 gene.

Immunostaining also confirmed a lack of CLC-3 expression in hippocampal CA3 region of the Clcn3 ${ }^{-1-}$ mice. Note the smaller size of the Clcn3 $3^{-/-}$ mice at P12 compared to WT mice. Scale bar $=10 \mu \mathrm{m}$. f Brain slice recordings revealed a voltage-dependent outward rectifying $\mathrm{Cl}^{-}$current in WT hippocampal CA3 pyramidal neurons, but not in CLC-3 KO neurons (P8-12). g I-V plot of voltage-dependent $\mathrm{Cl}^{-}$currents in WT (black) and CLC-3 $\mathrm{KO}$ (gray) neurons. The green curve shows no further inhibition of NaGluc on the remaining $\mathrm{Cl}^{-}$currents in CLC-3 KO neurons. $\mathbf{h}$ Typical immuno-fluorescent images showing different expression level of $\mathrm{CLC}-3 \mathrm{Cl}^{-}$channels in the hippocampus of neonatal (P11, left panel) and adult mice (3.5 months, right panel). The high magnification images of CA3 were placed in the up-left corner. Low magnification image scale bar = $200 \mu \mathrm{m}$; Inset scale bar $=10 \mu \mathrm{m}$. i Quantified data showing CLC-3 immunostaining intensity in neonatal and adult CA3 regions (unpaired Student's $t$-test, $P<0.001$ ). $\mathbf{j}, \mathbf{k}$ Western blot revealed a significant decrease of surface $\mathrm{CLC}-3 \mathrm{Cl}^{-}$channels in the adult hippocampus (MannWhitney test, $P<0.01$ ). Data are shown as mean \pm s.e.m., ${ }^{* *} P<0.01$, ${ }^{* * *} P<0.001$

channel-mediated $\mathrm{Cl}^{-}$currents (Additional file 1: Figure S3B, C), confirming previous report that NaGluc is an inhibitor of CLC-3 $\mathrm{Cl}^{-}$channels [27].

We further investigated why adult mouse brains lacked the voltage-dependent outward rectifying $\mathrm{Cl}$ - currents. Using both immunostaining and Western blot analyses (Fig. 3h-k), we found a significant downregulation of CLC-3 $\mathrm{Cl}^{-}$channels in the adult hippocampus, which is consistent with our electrophysiological results (Fig. 3a, b). Thus, CLC-3 $\mathrm{Cl}^{-}$channels undergo a significant developmental change during brain development, a phenomenon also widely reported for other channels and receptors [30, 31].

\section{CLC-3 $\mathrm{Cl}^{-}$channels contribute to recurrent ictal} epileptiform activity in the developing hippocampus Since we have discovered that NaGluc inhibited $\mathrm{Cl}^{-}$currents and epileptiform activity in neuronal cultures, we 
wondered whether $\mathrm{CLC}-3 \mathrm{Cl}^{-}$channels identified in neonatal brain slices may regulate epileptiform activity. We first examined the expression level of CLC-3 $\mathrm{Cl}^{-}$ channels after induction of epileptiform activity by treating neonatal brain slices with $0 \mathrm{Mg}^{2+}$ aCSF (artificial cerebral spinal fluid). Interestingly, epileptic stimulation significantly upregulated CLC-3 $\mathrm{Cl}^{-}$channels in neonatal brain slices (Fig. 4a, b; control, $11.2 \pm 1.5$ a.u., $n=10$; 0 $\mathrm{Mg}^{2+}, \quad 20.4 \pm 2.8$ a.u., $n=11 ; P<0.02$, Student's $t$-test; P8-P12). This upregulation of CLC-3 $\mathrm{Cl}^{-}$channels after epileptic stimulation was further confirmed by Western blot analysis (Fig. 4c, d). Consistent with these findings, whole-cell recordings revealed a significant increase of $\mathrm{Cl}^{-}$currents after $0 \mathrm{Mg}^{2+}$ treatment, which was also significantly inhibited by $20 \mathrm{mM}$ NaGluc (Fig. 4e, f; control, $31.2 \pm 1.8 \mathrm{pA} / \mathrm{pF}, n=15 ; 0 \mathrm{Mg}^{2+}$, $42.2 \pm 2.4 \mathrm{pA} / \mathrm{pF}, n=15, P<0.001 ;$ NaGluc, $7.3 \pm 0.6$ $\mathrm{pA} / \mathrm{pF}, n=11, P<0.001$; one-way ANOVA followed with Tukey post hoc tests). These results suggest that CLC-3 $\mathrm{Cl}^{-}$channels may be involved in regulation of neonatal epileptiform activity.

To further investigate the functional role of CLC-3 $\mathrm{Cl}^{-}$channels in neonatal epileptiform activity, we examined whether lack of CLC-3 $\mathrm{Cl}^{-}$channels in $\mathrm{KO}$ mice might have any effect on the induction of epileptiform activity in neonatal animals. Interestingly, while $0 \mathrm{Mg}^{2+}$ treatment quickly induced epileptiform burst activity in the hippocampal slices from WT

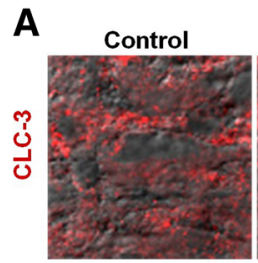

$\mathbf{E}$

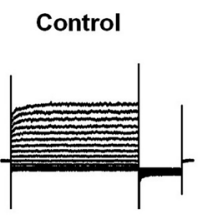

G

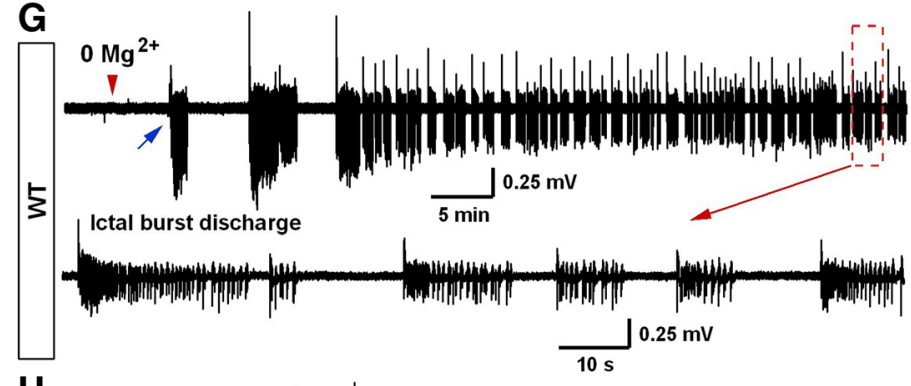

H

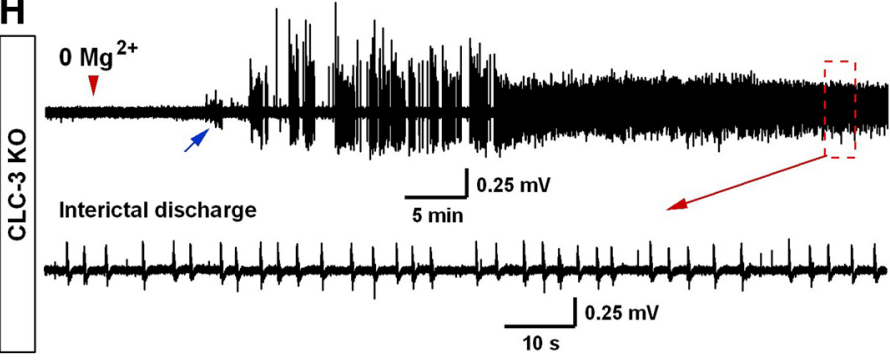

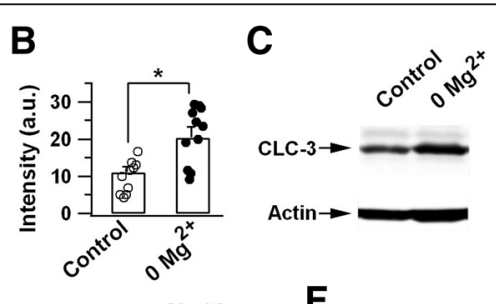

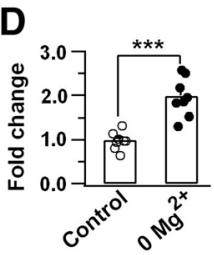

$0 \mathrm{Mg}^{2+} 1 \mathrm{~h}$
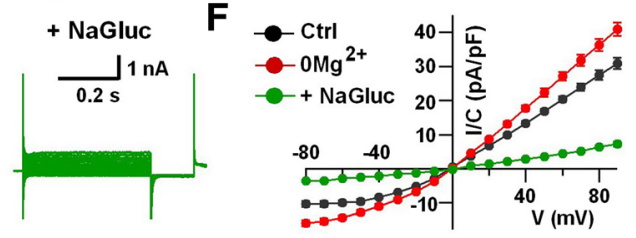

I

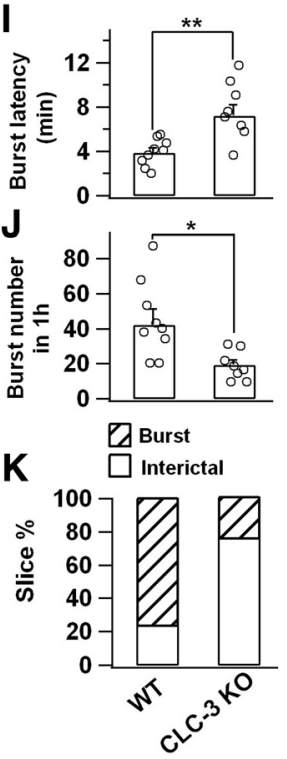

Fig. $4 \mathrm{CLC}-3 \mathrm{Cl}^{-}$channels and neonatal epileptiform activity. $\mathbf{a}$, b Immunostaining illustrating an upregulation of $\mathrm{CLC}^{-3} \mathrm{Cl}^{-}$channel expression after $0 \mathrm{Mg}^{2+}$ aCSF treatment $(1 \mathrm{~h})$. c, $\mathbf{d}$ Western blot analysis also confirmed an increase of $\mathrm{CLC}^{2} 3 \mathrm{Cl}^{-} \mathrm{channel}$ protein level after $0 \mathrm{Mg}{ }^{2+}$ treatment. Scale bar $=5 \mu \mathrm{m}$. e Representative voltage-dependent $\mathrm{Cl}^{-}$current traces in control, $0 \mathrm{Mg}^{2+}(1 \mathrm{~h})$, and $0 \mathrm{Mg}{ }^{2+}+20 \mathrm{mM} \mathrm{NaGluc}(1 \mathrm{~h}) \mathrm{conditions}$. $\mathbf{f}$-$\checkmark$ curves showing a significant increase of outward rectifying $\mathrm{Cl}^{-}$currents in $0 \mathrm{Mg}^{2+}$ aCSF group (red) and a remarkable inhibition by NaGluc (green). g, h Representative traces of epileptiform activity induced by $0 \mathrm{Mg}^{2+}$ aCSF in the hippocampal slices from WT (g) and CLC-3 KO mice (h) (P10-12). The blue arrowhead indicates the first ictal burst activity induced by $0 \mathrm{Mg}^{2+} \mathrm{aCSF}$. Note that in the neonatal hippocampal slices from CLC-3 KO mice, the initial epileptiform ictal burst activity later transformed into interictal single spikes (h). i, $\mathbf{j}$ Summarized data showing the burst latency (i) and burst number (j) induced by $0 \mathrm{Mg}^{2+}$ aCSF in hippocampal slices from WT and CLC-3 KO mice. $\mathbf{k}$ The percentage of slices showing ictal burst activity or interictal spike activity. Data are shown as mean \pm s.e.m., unpaired Student's t-test, ${ }^{*} P<0.05$, ${ }^{* *} P<0.01,{ }^{* * *} P<0.001$ 
neonatal mice (Fig. 4g), there was a significant delay in the onset of epileptiform activity in neonatal hippocampal slices from CLC-3 KO mice (Fig. 4h). Moreover, under $0 \mathrm{Mg}^{2+}$ treatment, WT hippocampal slices showed high frequency ictal bursts that lasted more than one hour during our continuous recordings (Fig. 4g, bottom enlarged trace), whereas the hippocampal slices from CLC-3 KO mice only showed transient ictal bursts and then turned into interictal single spikes (Fig. $4 \mathrm{~h}$, bottom enlarged trace). Quantitatively, the latency to the onset of ictal burst activity increased by $86.2 \%$ in the CLC-3 KO slices compared to the control WT slices (Fig. 4i); and after $0 \mathrm{Mg}^{2+}$ treatment $(1 \mathrm{~h})$, while $77.8 \%$ of WT slices $(n=9)$ showed continuous ictal burst activity, the CLC-3 KO slices displayed mainly interictal single spikes $\left(75 \%, n=8, P<0.01, \mathrm{X}^{2}\right.$ test) after initial transient bursts (Fig. 4j, k). These results indicate that the absence of CLC-3 $\mathrm{Cl}^{-}$channels may disrupt the sustainability of ictal epileptiform bursts.
Inhibition of $\mathrm{CLC}-3 \mathrm{Cl}^{-}$channels suppresses epileptiform activity in the developing hippocampus

The reduced epileptiform activity in neonatal CLC-3 KO mice prompted us to test whether inhibiting CLC-3 $\mathrm{Cl}^{-}$ channels by NaGluc would have any effect on epileptiform activity in neonatal brain slices. Interestingly, we observed a significant age-dependent difference in the effect of NaGluc on the epileptiform activity induced by $0 \mathrm{Mg}^{2+}$ treatment. Specifically, NaGluc $(20 \mathrm{mM})$ strongly inhibited the epileptiform activity in neonatal hippocampal slices (P7-P12) (Fig. 5a, b). However, in 1-month old animals (P26), the inhibitory effect of NaGluc on epileptiform activity became much smaller (Fig. 5c, d). Quantitatively, NaGluc $(20 \mathrm{mM})$ inhibited $60 \%$ of the average power of epileptiform activity in early postnatal animals (P6-8, $59.6 \pm 4.3 \%, n=10 ; \mathrm{P} 10-12,62.1 \pm 3.8 \%$, $n=10 ; P<0.001$, paired Student's $t$-test), but only reduced $20 \%$ of the power in older animals after weaning (P21-33, $23.8 \pm 4.1 \%, n=7 ; P<0.005$, paired Student's
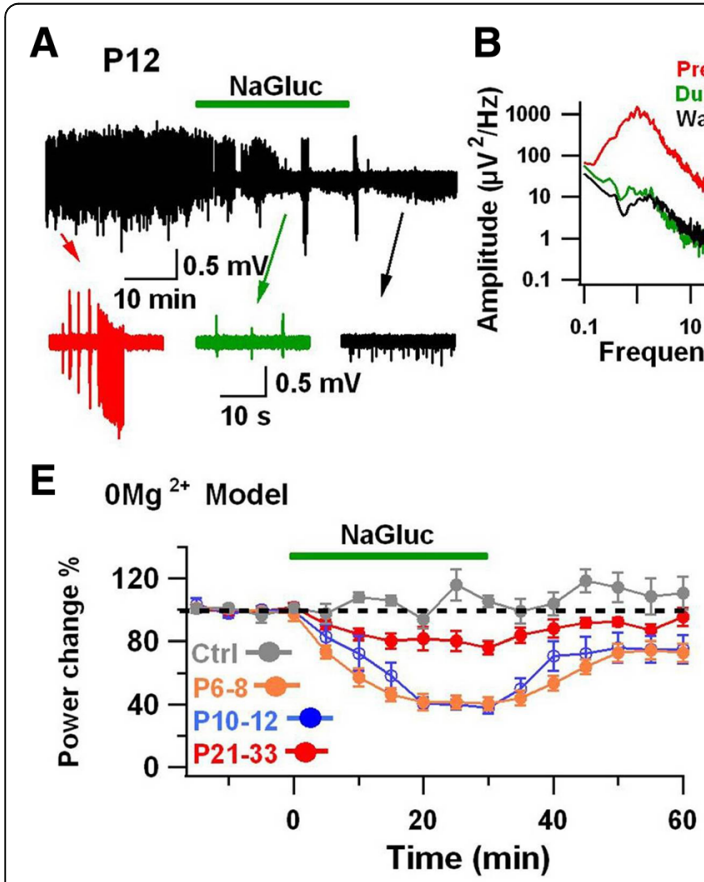

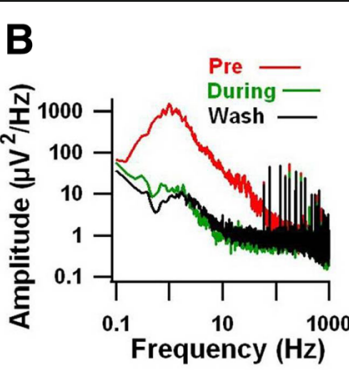$$
\text { c }
$$
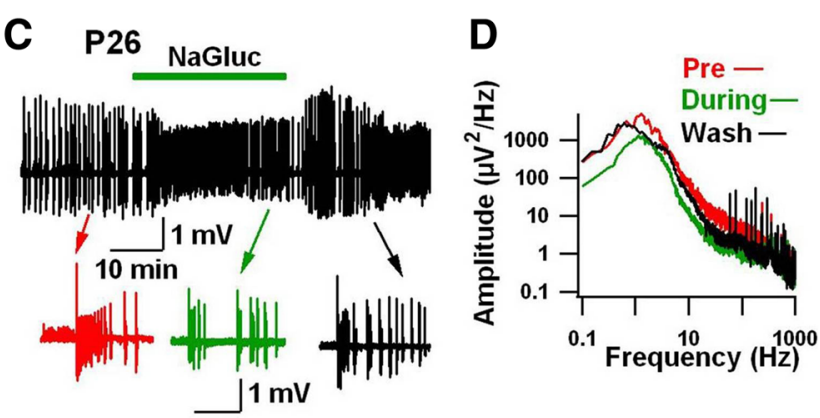

$10 \mathrm{~s}$
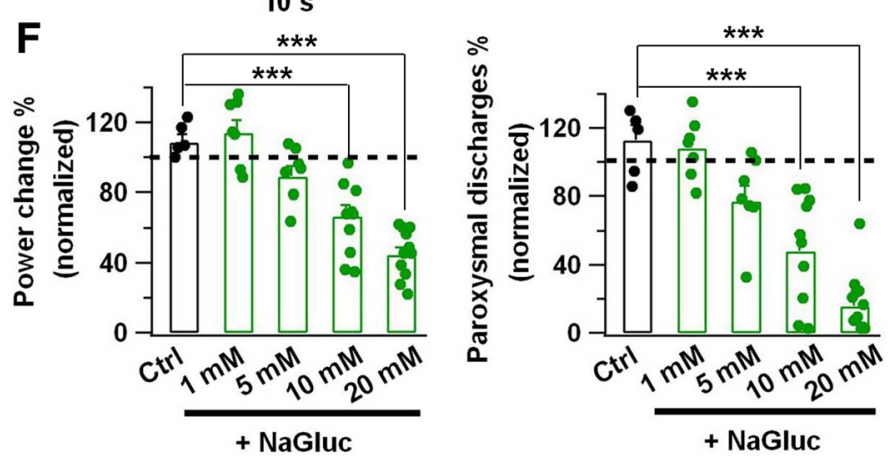

Fig. 5 Suppressing neonatal epileptiform activity through inhibiting CLC-3 channels. a Field potential recording showing strong inhibition of epileptiform activity $\left(0 \mathrm{Mg}^{2+}\right)$ by NaGluc $(20 \mathrm{mM})$ in the CA3 pyramidal layer of hippocampal slices from neonatal mice (P12). b Power spectra of epileptiform activity (5-min time windows) before (red), during (green), and after (black) NaGluc application. The amplitude of power (integrative area under the power spectrum trace) was significantly reduced after NaGluc application. c, d In P26 hippocampal slices, however, NaGluc only showed modest inhibitory effect on the epileptiform activity. e Normalized power showing the time course of NaGluc inhibition on the epileptiform activity induced by $0 \mathrm{Mg}^{2+}$ aCSF. NaGluc dramatically reduced the power of epileptiform activity in the P6-8 and P10-12 neonatal slices $(P<0.001$, paired Student's $t$-test). As a control, the gray line represents the effect of adding $20 \mathrm{mM} \mathrm{NaCl}$ on neonatal (P8-12) epileptiform activity, there was no significant change $(P>0.1$, paired Student's t-test). $\mathbf{f}$ Dose-dependent inhibition of NaGluc on the power (left) and paroxysmal discharges (right) in the neonatal brain slices. The percentage change of power and paroxysmal discharges were normalized to the 20 min of stable recordings before $\mathrm{NaCl}$ or NaGluc application. Control (Ctrl) represents the effect of $20 \mathrm{mM} \mathrm{NaCl}$. Compared to control, the power and paroxysmal discharges were significantly reduced in the presence of $10 \mathrm{mM}$ or $20 \mathrm{mM}$ NaGluc. Data are shown as mean \pm s.e.m. *** $P<0.001$ 
$t$-test) (Fig. 5e). Moreover, gluconate inhibition of epileptiform activity in neonatal slices showed a clear dose-dependence (Fig. 5f). To exclude the effects of osmolarity change by adding NaGluc ( $2 \mathrm{ml}$ of $1 \mathrm{M}$ NaGluc stock solution), we also added $2 \mathrm{ml}$ of $1 \mathrm{M} \mathrm{NaCl}$ stock solution into the $0 \mathrm{Mg}^{2+}$ aCSF, and found that the neonatal epileptiform activity was not significantly changed (Fig. 5e, Ctrl). The age differences in the NaGluc inhibition of epileptiform activity coincides well with the different amplitudes of $\mathrm{Cl}^{-}$currents observed in neonatal and adult brain slices (Fig. 3a, b), further supporting a close link between CLC-3 $\mathrm{Cl}^{-}$channels and neonatal epileptiform activity.

Besides $0 \mathrm{Mg}^{2+}$ stimulation, we further examined whether NaGluc could inhibit neonatal epileptiform activity induced by other hyperexcitatory stimulation. We first tested 4-AP model by adding $\mathrm{K}^{+}$channel blocker 4-AP $(50 \mu \mathrm{M})$ into the $0 \mathrm{Mg}^{2+}$ aCSF to induce robust epileptiform activity (Additional file 1: Figure S4A). Addition of $20 \mathrm{mM} \mathrm{NaGluc}$ to the $4-\mathrm{AP}+0 \mathrm{Mg}^{2+}$ aCSF significantly reduced the epileptiform activity in neonatal hippocampal slices (Additional file 1: Figure S4A-C; $70.2 \pm 5.3 \%$ reduction of the power amplitude by NaGluc, $n=9 ; \quad P<0.001$, paired Student's $t$-test). The second test was on a high $\mathrm{K}^{+}$model, where elevated extracellular $\mathrm{K}^{+}(8.5 \mathrm{mM})$ was used to induce epileptiform activity (Additional file 1: Figure S4D). Similarly, addition of $20 \mathrm{mM}$ NaGluc into the high $\mathrm{K}^{+}$aCSF dramatically reduced the epileptiform burst activity in neonatal hippocampal slices (Additional file 1: Figure S4D-F, NaGluc reduced the power amplitude by $70.8 \pm 4.9 \%, n=5$; $P<0.001$, paired Student's $t$-test). In summary, our results demonstrate that gluconate is an anti-epileptiform activity agent in the neonatal animals.

We further identified that $\beta-\mathrm{HB}$, a ketone body generated in the liver under ketogenic diet, is an inhibitor of CLC-3 chloride channels. Ketone bodies (acetoacetate and $\beta-\mathrm{HB}$, purchased from TCI) are produced in the liver, released into the circulatory system, transported into the brain through monocarboxylate transporter, and then serve as the substrates for energy production in the brain but later also found as anti-epileptic agents [32, 33]. Ketone bodies and gluconic acid are both organic acids. $\beta-\mathrm{HB}$ and gluconate, in particular, have similar structures and are both hydroxyl-containing monocarboxylates. Thus, we hypothesized that $\beta-\mathrm{HB}$ might be another inhibitor for CLC-3 chloride channels. We found that $\mathrm{Cl}^{-}$current was indeed inhibited by $\beta-\mathrm{HB}$ but not acetoacetate (Additional file 1: Figure S5A). The $\mathrm{IC}_{50}$ of $\beta-\mathrm{HB}$ on the $\mathrm{Cl}^{-}$currents in neonatal hippocampal neurons was about $6.2 \mathrm{mM}$ (Additional file 1: Figure S5B). When we replaced glucose with $\beta-\mathrm{HB}$ in the recording medium, the epileptiform activity was significantly suppressed
(Additional file 1: Figure S5C, D). The average power of epileptiform activity was decreased by $44.5 \% \pm 3.2 \%$ (Additional file 1: Figure S5E, $n=7$ ). These data suggest that the CLC-3 $\mathrm{Cl}^{-}$channel might be a potential target of the ketone bodies.

\section{Gluconate inhibits neonatal seizure activity in vivo}

Following brain slice work, we further investigated the effect of gluconate on in vivo seizure activity in neonatal and adult animals. We employed a commonly used seizure model induced by a neurotoxin kainic acid (KA) [12]. Because neonatal mice were too small for in vivo EEG recordings, we injected $\mathrm{KA}(2 \mathrm{mg} / \mathrm{kg}$, i.p.) into neonatal rats (P10-12) to elicit robust seizure activities as revealed by EEG recordings (Fig. 6a, b) [12]. Importantly, when NaGluc ( $2 \mathrm{~g} / \mathrm{kg}$, i.p.) was injected $10 \mathrm{~min}$ after KA injection, the epileptic seizure activity was inhibited in neonatal animals (Fig. 6c, d). Furthermore, we compared the anti-epileptic effect of gluconate with previously reported anti-convulsant drugs such as phenobarbital and bumetanide in neonatal animals. Phenobarbital is currently the drug of first choice to treat neonatal seizures, despite only $\sim 50 \%$ efficacy and potential negative neurodevelopmental consequences [34]. Bumetanide is a loop diuretic, currently under evaluation as a potential antiepileptic drug [10]. Both phenobarbital $(25 \mathrm{mg} / \mathrm{kg}$, i.p.) and bumetanide $(0.2 \mathrm{mg} /$ $\mathrm{kg}$, i.p.) also inhibited seizure activity to a certain degree in neonatal animals (Fig. 6e-h). Quantitatively, when we calculated the EEG power in the last 30 min during our 2 - $\mathrm{h}$ recording period after $\mathrm{KA}$ injection, we found that the relative power was reduced by $72.3 \%$ in NaGluc group, $35.5 \%$ in phenobarbital group, and $54.3 \%$ in bumetanide group, respectively (Fig. 6m). We further analyzed the anti-epileptic effect of gluconate in adult animals. Compared to the significant inhibition of neonatal seizure, gluconate showed less inhibition of adult seizure activity (Fig. 6i-l and n), consistent with our results in brain slice recordings (Fig. 5a-e). Therefore, we conclude that NaGluc may be a new anti-epileptic drug to treat neonatal seizures.

Besides KA-induced neonatal seizure model, we further investigated the effect of gluconate on a more clinically relevant neonatal seizure model induced by hypoxia-ischemia (HI) stimulation $[35,36]$. Combining ischemia (right common carotid artery ligation) with hypoxia $\left(10 \% \mathrm{O}_{2}\right.$ for $2 \mathrm{~h}$ ) stimulation (see Additional file 1: Figure S6 for experimental illustration), we were able to observe clear epileptic seizure activity through EEG recordings in neonatal rats (Additional file 1: Figure S7A and B). Importantly, application of NaGluc $(2 \mathrm{~g} / \mathrm{kg}$, i.p.) significantly reduced the $\mathrm{HI}$-induced seizure activity (Additional file 1: Figure S7C and D). Similarly, phenobarbital (25 mg/kg, i.p.) also inhibited the HI-induced 


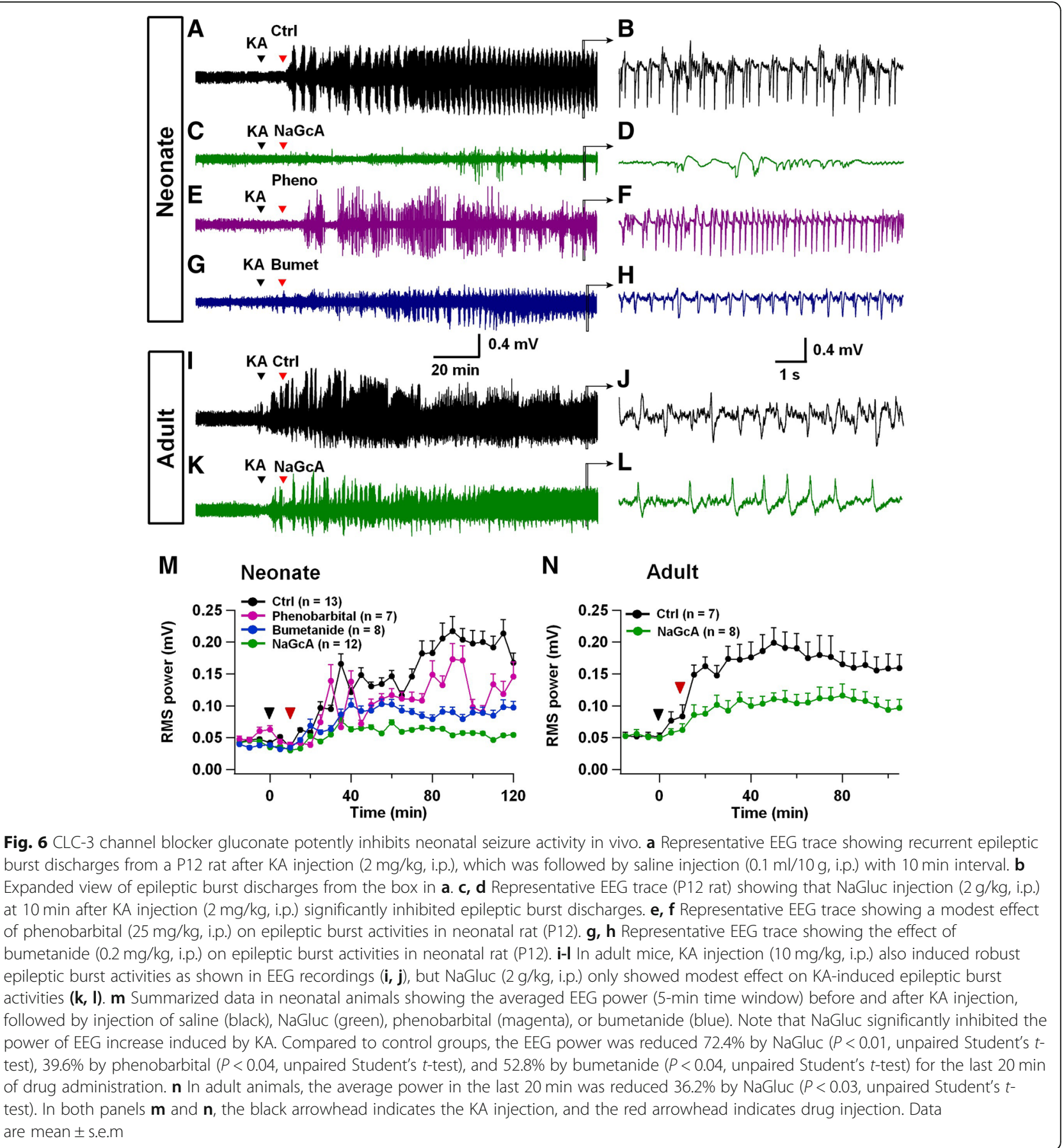

seizure activity in neonatal animals (Additional file 1: Figure S7E and F). Unexpectedly, addition of gluconate and phenobarbital together even more strongly suppressed the seizure activity (Additional file 1: Figure S7G and H), suggesting a potential synergistic effect between these two drugs. Quantitatively, both the seizure burst number and burst duration were significantly reduced by NaGluc or phenobarbital, and no bursts were detected in the presence of both drugs (Additional file 1: Figure S7I and J).
Therefore, combining NaGluc together with phenobarbital may yield a novel treatment for neonatal seizures.

\section{CLC-3 $\mathrm{Cl}^{-}$channels regulate $\mathrm{Cl}^{-}$homeostasis in neonatal neurons}

Since knocking out or inhibiting CLC-3 $\mathrm{Cl}^{-}$channels significantly suppresses the neonatal epileptiform activity, we investigated the underlying mechanism underlying the CLC-3 $\mathrm{Cl}^{-}$channels and epileptiform activity. 


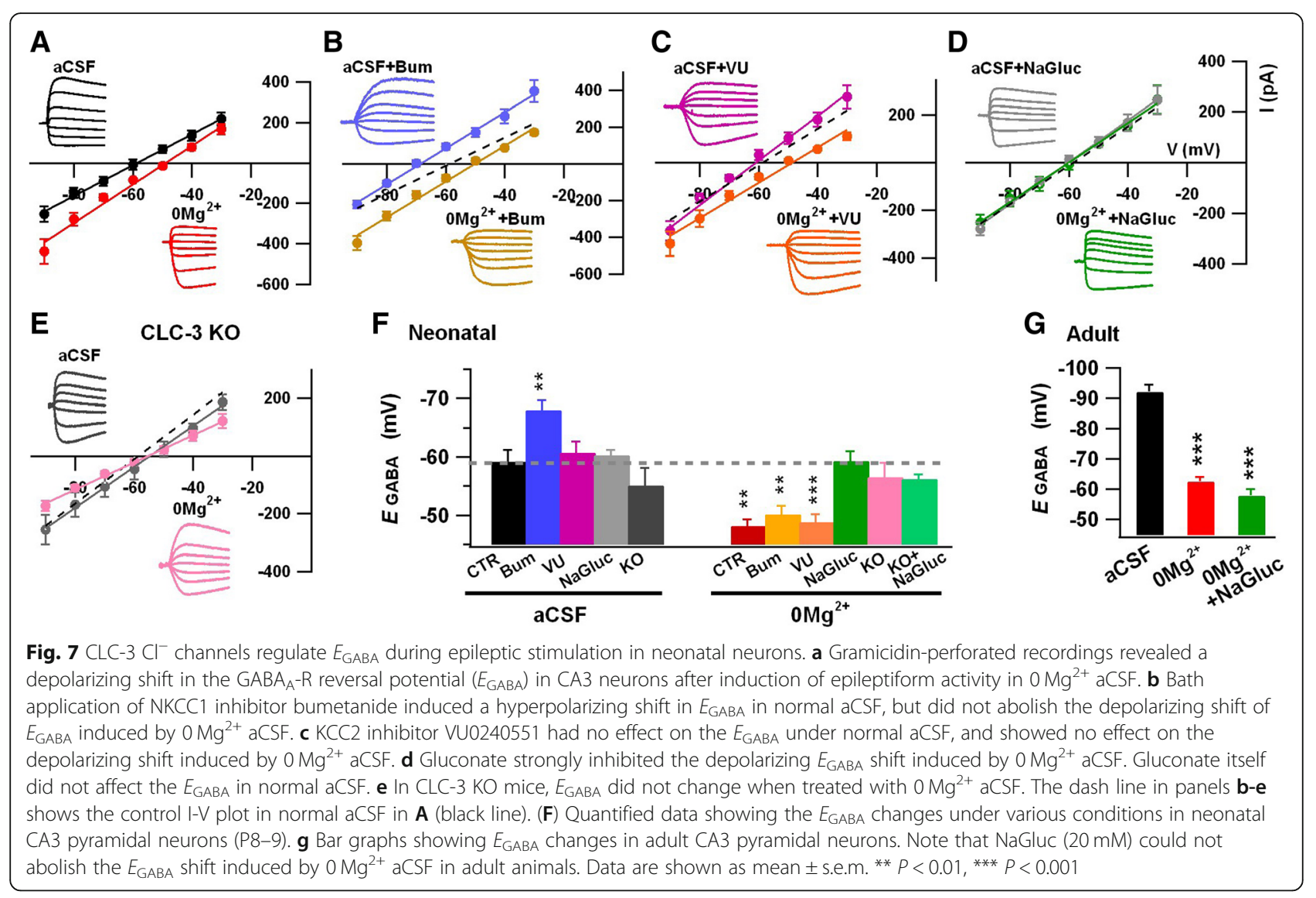

Because CLC-3 $\mathrm{Cl}^{-}$channel is a voltage-dependent outward rectifying $\mathrm{Cl}^{-}$channel, we hypothesize that CLC-3 $\mathrm{Cl}^{-}$channels may regulate $\mathrm{Cl}^{-}$homeostasis, which will in turn affect GABA function and recurrent ictal burst epileptiform activity. Using gramicidin-perforated wholecell recordings to keep $\left[\mathrm{Cl}^{-}\right]_{\mathrm{i}}$ intact, we found that epileptic stimulation with $0 \mathrm{Mg}^{2+}$ aCSF $\left(32{ }^{\circ} \mathrm{C}\right.$ for $1 \mathrm{~h}$ ) induced a depolarizing shift in $E_{\mathrm{GABA}}$ in neonatal hippocampal CA3 pyramidal neurons (P8-9, aCSF: - 59.2 \pm $2.0 \mathrm{mV}, n=13 ; 0 \mathrm{Mg}^{2+}$ : $-48.2 \pm 1.1 \mathrm{mV}, n=10$ ) (Fig. 7a). Treatment of neonatal slices with bumetanide (Bum, $10 \mu \mathrm{M})$, a specific blocker for NKCC1 at low concentration, induced a hyperpolarizing shift in $E_{\mathrm{GABA}}$ in the normal condition (Fig. 7b, blue line, dashed line indicates control $E_{\mathrm{GABA}}$ ), because NKCC1 imports $\mathrm{Cl}^{-}$into neuronal cells [10-12]. However, in the presence of bumetanide, epileptic stimulation still elicited a depolarizing shift of $E_{\mathrm{GABA}}$, suggesting that a factor other than NKCC1 is regulating $E_{\mathrm{GABA}}$ during epileptic stimulation (Fig. 7b, yellow line; Bum, $-68.0 \pm 1.7 \mathrm{mV}, n=9 ; 0 \mathrm{Mg}^{2+}$ + Bum, $-50.2 \pm 1.4 \mathrm{mV}, n=9 ; P<0.002)$. Treatment with KCC2 blocker VU0240551 $(10 \mu \mathrm{M})$ did not affect the $E_{\mathrm{GABA}}$ in neonatal animals (Fig. 7c, purple line; $-60.8 \pm$ $1.9 \mathrm{mV}, n=6$ ), possibly due to a low expression level of
KCC2 at this early time [8, 11, 12]; and epileptic stimulation still elicited a positive shift in $E_{\mathrm{GABA}}$ (Fig. 7c, orange line; $-48.9 \pm 1.3 \mathrm{mV}, n=8$ ). Therefore, the $E_{\mathrm{GABA}}$ shift induced by epileptic stimulation in neonatal CA3 pyramidal neurons is not controlled by $\mathrm{NKCC} 1$ or $\mathrm{KCC} 2$.

Then, we asked whether CLC-3 $\mathrm{Cl}^{-}$channels are involved in the $E_{\mathrm{GABA}}$ shift induced by epileptic stimulation. Interestingly, when we inhibited CLC-3 $\mathrm{Cl}^{-}$channels with NaGluc $(20 \mathrm{mM})$, the $E_{\mathrm{GABA}}$ was not altered by epileptic stimulation (Fig. $7 \mathrm{~d} ; 0 \mathrm{Mg}^{2+}+\mathrm{NaGluc}$ : $59.3 \pm 1.7 \mathrm{mV}, n=6$ ). Furthermore, in CLC-3 KO mice, the $E_{\mathrm{GABA}}$ also remained unchanged by epileptic stimulation (Fig. 7e; CLC-3 KO + $0 \mathrm{Mg}^{2+}:-55.6 \pm 2.1 \mathrm{mV}, n=10$ ), and application of NaGluc to CLC-3 KO neurons had no additive effect on $E_{\mathrm{GABA}}(-56.6 \pm 2.4 \mathrm{mV}, n=5)$. Importantly, inhibiting CLC-3 channels with NaGluc or knockout of CLC-3 channels did not change the $E_{\mathrm{GABA}}$ in normal conditions (Fig. 7f; NaGluc: $-60.3 \pm 0.9 \mathrm{mV}, n=5$; CLC-3 KO: $-55.4 \pm 2.9 \mathrm{mV}, n=9$ ). In older animals (P30-90), however, NaGluc showed no effect on the $E_{\mathrm{GABA}}$ shift induced by epileptic stimulation (Fig. $7 \mathrm{~g}$ ), consistent with our observation that CLC-3 channelmediated $\mathrm{Cl}^{-}$current is greatly reduced in the adult 
animals (Fig. 3a, b). Together, our results suggest that CLC-3 $\mathrm{Cl}^{-}$channels play a critical role in controlling $E_{\mathrm{GABA}}$ during epileptic stimulation in neonatal animals.

\section{CLC-3 $\mathrm{Cl}^{-}$channels modulate GABA function}

Since GABAergic transmission plays an important role in recurrent seizure activity [37, 38], we wondered whether $\mathrm{CLC}-3 \mathrm{Cl}^{-}$channels might modulate GABA function in the developing brain. To test this idea, we investigated the effect of $\mathrm{NaGluc}$ on $\mathrm{GABA}_{\mathrm{A}}-\mathrm{R}$ currents under conditions mimicking epileptic stimulation. We observed that $0 \mathrm{Mg}^{2+}$ aCSF-induced epileptiform bursts often lasted more than $10 \mathrm{~s}$ in the neonatal CA3 pyramidal neuron (Fig. 8a). To investigate the effect of such long-lasting epileptiform bursts on GABA function, we performed gramicidin-perforated whole-cell recordings to keep the intracellular $\mathrm{Cl}^{-}$intact in neonatal brain slices [7]. We recorded $G_{A B A}-\mathrm{R}$ currents induced by isoguvacine $(100 \mu \mathrm{M}, 50 \mathrm{~ms})$, an agonist for $\mathrm{GABA}_{\mathrm{A}}-\mathrm{Rs}$, before and after a membrane-depolarizing shift $(40 \mathrm{mV}$ for $10 \mathrm{~s}$, holding potential was set at $-70 \mathrm{mV}$ ) that mimicked the epileptiform burst activity. Interestingly, the $\mathrm{GABA}_{\mathrm{A}}-\mathrm{R}$ current (excitatory current, $\mathrm{Cl}^{-}$efflux through the $\mathrm{GABA}_{\mathrm{A}}-\mathrm{Rs}$ ) was significantly increased after membrane depolarization in WT neurons but not in CLC-3 $\mathrm{KO}$ neurons, nor in the presence of CLC-3 channel blocker NaGluc (Fig. 8b, c). It appears that depolarizing stimulation activates $\mathrm{CLC}-3 \mathrm{Cl}^{-}$channels, and the $\mathrm{Cl}^{-}$ influx through CLC-3 $\mathrm{Cl}^{-}$channels leads to intracellular accumulation of $\mathrm{Cl}^{-}$, which in turn enhances the GABA excitation (Fig. 8b, the working model).

To further test this hypothesis, we directly measured GABA-induced neuronal activity in neonatal brain slices (P8-9). Cell-attached recordings were performed to monitor neuronal firing activity elicited by local application of $\mathrm{GABA}_{\mathrm{A}}-\mathrm{R}$ agonist isoguvacine $(10 \mu \mathrm{M}, 30 \mathrm{~s})$ [39]. The majority of CA3 pyramidal neurons in the resting condition did not respond to isoguvacine (Fig. 8d, control, $n=32$ ). However, after $0 \mathrm{Mg}^{2+}$ treatment, $68 \%$ of neurons showed spike activity upon isoguvacine

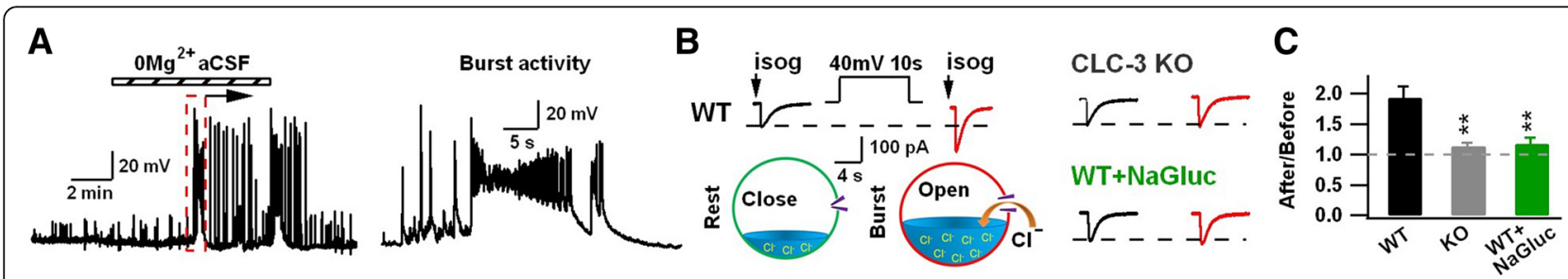

D

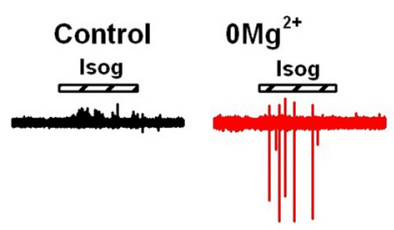

$\mathbf{F}$

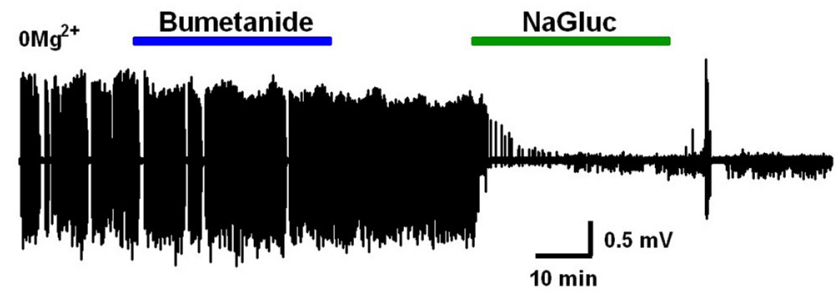

$\mathrm{OMg}^{2+}+\mathrm{Bum} \quad \mathrm{OMg}^{2+}+\mathrm{VU}$
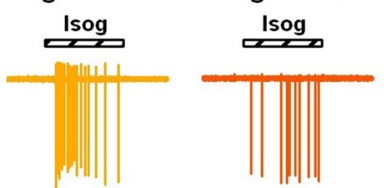

$\mathrm{OMg}^{2+}+\mathrm{NaGluc}$
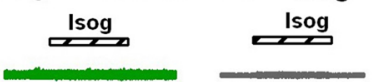

G

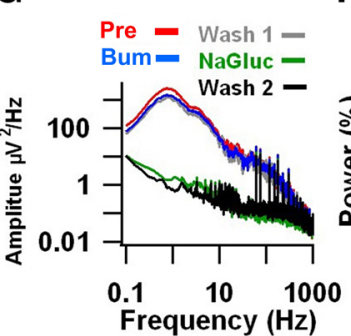

E

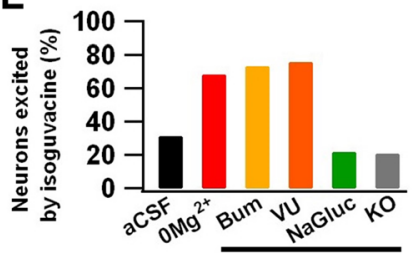

H

$\mathrm{OMg}^{2+}$

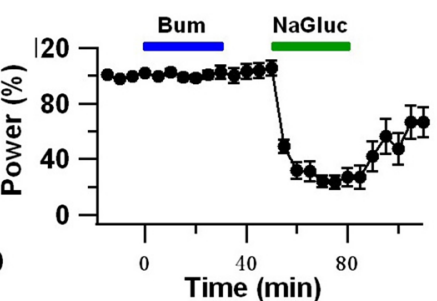

Fig. $8 \mathrm{CLC}-3$ activation regulates GABA excitation in the developing neurons. a Epileptiform burst activity induced by $0 \mathrm{Mg}^{2+}$ aCSF in neonatal CA3 neurons showed long-lasting membrane depolarization. b A long-lasting membrane depolarization pulse (40 mV, 10 s), mimicking the

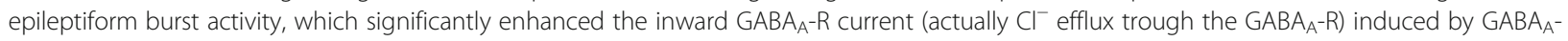
$\mathrm{R}$ agonist isoguvacine $(100 \mu \mathrm{M})$ under gramicidin-perforated whole-cell recording. Such depolarization-induced enhancement was absent in CLC$3 \mathrm{KO}$ mice and strongly inhibited by CLC-3 channel blocker NaGluc $(20 \mathrm{mM})$. c Summarized data of the long-lasting membrane depolarization effect on the inward GABA - - current in WT, CLC-3 KO, and WT + NaGluc groups. ${ }^{*} P<0.01$. d Typical traces of cell-attached recording showing the spike activity induced by isoguvacine $(10 \mu \mathrm{M}, 30 \mathrm{~s})$ under different conditions in neonatal animals (P8-9). e Summarized data showing the percentage of neurons excited by isoguvacine. Note that $\mathrm{CLC}-3 \mathrm{KO}$ and $\mathrm{NaGluc}$ significantly inhibited the GABA excitatory activity induced by 0 $\mathrm{Mg}^{2+}$ aCSF. $\mathbf{f}$ Comparison between the effects of bumetanide and $\mathrm{NaGluc}$ on epileptiform activity induced by $0 \mathrm{Mg}^{2+}$ in neonatal brain slices. $\mathbf{g}$, h Power analysis illustrated a significant reduction of power after NaGluc application (68.9\% reduction in presence of NaGluc, $P<0.001$, paired Student's $t$-test) but not bumetanide application ( $P>0.7$, paired Student's $t$-test). Data are shown as mean \pm s.e.m 
application (Fig. 8d, $0 \mathrm{Mg}^{2+}, n=19$ ). Blocking NKCC1 with bumetanide (Fig. $8 \mathrm{~d}, 0 \mathrm{Mg}^{2+}+$ Bum, $n=19$ ) or blocking KCC2 with VU0240551 (Fig. $8 \mathrm{~d}, 0 \mathrm{Mg}^{2+}+\mathrm{VU}$, $n=21$ ) did not change the percentage of neurons excited by isoguvacine. In contrast, knock out of CLC-3 or application of NaGluc to inhibit $\mathrm{CLC}-3 \mathrm{Cl}^{-}$channels significantly decreased the percentage of neurons excited by isoguvacine after $0 \mathrm{Mg}^{2+}$ treatment (Fig. $8 \mathrm{~d}, 0 \mathrm{Mg}^{2+}+$ NaGluc, $n=18$; CLC-3 KO, $n=19$; quantified in Fig. 8e). These differential results of Bum and NaGluc on $E_{\mathrm{GABA}}$ and GABA activity suggest that $\mathrm{NKCC} 1 \mathrm{Cl}^{-}$transporters and $\mathrm{CLC}-3 \mathrm{Cl}^{-}$channels may play different functions in the recurrent epileptiform activity in the neonatal brain.

We then directly compared the effects of NKCC1 $\mathrm{Cl}^{-}$ transporter inhibitor (Bum) versus $\mathrm{CLC}-3 \mathrm{Cl}^{-}$channel inhibitor (NaGluc) on neonatal epileptiform activity induced by $\mathrm{Mg}^{2+}$-free aCSF in neonatal hippocampal slices. After induction of epileptiform activity, we first applied Bum $(10 \mu \mathrm{M})$ followed by NaGluc $(20 \mathrm{mM})$. Blocking NKCC1 with Bum did not change the epileptiform activity induced by $0 \mathrm{Mg}^{2+}$ aCSF (Fig. 8f-h), which is consistent with a previous study [40]. In contrast, application of NaGluc dramatically reduced the epileptiform activity in the same slices (Fig. 8f, g). Quantified data showed that the power was reduced $\sim 70 \%$ during $\mathrm{NaGluc}$ application (Fig. 8h; $p<0.001$, paired Student's $t$-test, $n=8$, P7-P9 pups), but no change was observed in bumetanide application (Fig. 8h). Therefore, we conclude that gluconate may inhibit neonatal seizure activity through blocking CLC-3 $\mathrm{Cl}^{-}$channels and stabilizing intracellular $\mathrm{Cl}^{-}$homeostasis.

\section{Discussion}

In this study, we discovered that gluconate inhibits neonatal seizures through blocking CLC-3 $\mathrm{Cl}^{-}$channels. Interestingly, $\mathrm{CLC}-3 \mathrm{Cl}^{-}$channels mediate a large voltage-dependent $\mathrm{Cl}^{-}$current in neonatal brains, but not adult brains. Such developmental change of CLC-3 $\mathrm{Cl}^{-}$ channels coincides with a strong inhibition of gluconate on neonatal seizure activity but a moderate effect on adult seizure activity. Mechanistically, we demonstrate that CLC-3 $\mathrm{Cl}^{-}$channels regulate $\mathrm{Cl}^{-}$homeostasis and GABA function in neonatal neurons. Together, our studies demonstrate that gluconate suppresses neonatal seizure activity through the inhibition of CLC-3 $\mathrm{Cl}^{-}$channels.

Previous studies have linked $\mathrm{Cl}^{-}$channels in the CLC family to human epilepsy but the mechanism is not well understood. Mutations in CLC-1 channels have been identified in idiopathic epileptic patients [41]. CLC-2 channel mutations have also been found in human patients but some studies suggest that the mutations may not contribute to epilepsy [42-44]. CLC-3 channels are widely expressed in different brain areas, and the hippocampus is one of the highest expression regions
$[45,46]$. While the hippocampus is known to be one of the most epileptogenic structures in the brain, there has been little study directly investigating the relationship between CLC-3 channels and neonatal seizure, except a report that CLC-3 knock-out mice showed resistance to PTZ-induced seizure activity [20]. Our work provided a direct link between CLC-3 $\mathrm{Cl}^{-}$channels and neonatal seizure.

CLC-3 chloride channels are members of an extended family of voltage-dependent chloride channels and transporters, with multiple functional properties and subcellular locations [28, 47]. The CLC-3 chloride channel is encoded by CLCN3 gene, which has 9 protein coding splice variants in the human genome and 5 in the mouse (Ensembl database). In 2015, it was found that the different splice variants of CLC-3 have different spatial distributions in the cell [21]. Interestingly, one of the neuronal CLC-3 splice variants, CLC-3c, prefers to locate at plasma membranes. After overexpressing in HEK293T cells, whole cell recordings revealed the outward rectifying $\mathrm{Cl}^{-}$currents that were mediated by the CLC-3c channels. Meanwhile, they also found that the CLC-3c in the hippocampus was slightly down-regulated during development [21]. Consistent with this, we have confirmed that plasma membrane CLC-3 $\mathrm{Cl}^{-}$channels are significantly down-regulated in the hippocampus during brain development, which may be due to a potential change in the CLC-3 splice variants reported recently [21]. A significant developmental change of CLC-3 $\mathrm{Cl}^{-}$channels is reminiscent of many other channel and receptor changes during brain development [30, 31, 48]. CLC-3 channel-mediated $\mathrm{Cl}^{-}$currents have also been recorded in cultured hippocampal neurons [18], which is consistent with our recordings in the hippocampal slices. In addition to neurons, CLC-3 channelmediated $\mathrm{Cl}^{-}$currents have also been detected in other types of cells [27, 49]. Our studies demonstrate that CLC-3 $\mathrm{Cl}^{-}$channel-mediated currents regulate the intracellular $\mathrm{Cl}^{-}$homeostasis, which in turn affects GABA function in the neonatal brains.

Plasma membrane depolarization will activate CLC-3 $\mathrm{Cl}^{-}$channels, leading to a large amount of $\mathrm{Cl}^{-}$influx that will significantly change the $\left[\mathrm{Cl}^{-}\right]_{\text {in }}$. Therefore, in addition to NKCC1, CLC-3 also plays an important role in regulating intracellular $\mathrm{Cl}^{-}$homeostasis in the developing brain. However, these transporters may play different roles due to their differences in voltage dependence. At rest, voltage-sensitive CLC-3 $\mathrm{Cl}^{-}$channels are relatively silent, and therefore $\mathrm{Cl}^{-}$transporters such as NKCC1 are the major players that maintain $\left[\mathrm{Cl}^{-}\right]_{i}$ in developing neurons $[8,11,50]$. During epileptic stimulation, however, $\mathrm{CLC}-3 \mathrm{Cl}^{-}$channels are activated and the large $\mathrm{Cl}^{-}$influx significantly increases $\left[\mathrm{Cl}^{-}\right]_{\mathrm{i}}$, resulting in GABA over-excitation and recurrent ictal seizure 
activity. In supporting this novel hypothesis, we demonstrate that neonatal CLC-3 knockout slices do not have large outward rectifying $\mathrm{Cl}^{-}$current, and consequently the recurrent ictal burst activity is transformed to the interictal activity. Similarly, blocking $\mathrm{CLC}-3 \mathrm{Cl}^{-}$channels with gluconate strongly inhibits neonatal seizure bursts, possibly through disrupting the positive feedback loop between CLC-3 $\mathrm{Cl}^{-}$channels and recurrent ictal burst activity. In conclusion, we have identified the CLC-3 $\mathrm{Cl}^{-}$channel as a novel target for suppressing robust epileptiform activity in the developing brain and found that gluconate can inhibit neonatal epileptiform activity by blocking CLC-3 $\mathrm{Cl}^{-}$channels. Since CLC-3 $\mathrm{Cl}^{-}$channels also regulate NMDA receptors and GABAergic synaptic transmission [18, 28], gluconate may also suppress neonatal seizure activity through modulating NMDA receptors and GABAergic synaptic transmission. These questions deserve further study in the future.

Gluconic acid is a large organic anion, often used as a food or drug additive in a salt form such as magnesium gluconate, calcium gluconate, or potassium gluconate, where gluconate was used as an inactive ingredient to deliver cations. However, the functional role of gluconate itself was largely neglected in the past. One case study reported that an epileptic patient was treated with Ca-gluconate and then epileptic jerks faded [51]. The authors attributed this effect to $\mathrm{Ca}^{2+}$, but whether gluconate might have played any role was completely ignored. Notably, gluconic acid is a polyhydroxycarboxylic acid, with divalent cation chelating capability especially in alkaline solutions [52]. Since $\mathrm{Ca}^{2+}$ is very important for neurotransmission, the divalent cation chelation of gluconic acid might have an effect on the epileptiform activity. However, we demonstrate here that the $\mathrm{Ca}^{2+}$ current is not affected by bath application of gluconate under the physiologic $\mathrm{pH}$ (7.3-7.4), confirming that gluconate chelation depends on alkaline conditions. Moreover, we also directly compared the antiepileptic effect of gluconate between neonatal and adult rodents, and found a stronger inhibition in neonate animals than the adults. Together, we conclude that gluconate inhibits neonate seizure through inhibiting $\mathrm{CLC}-3 \mathrm{Cl}^{-}$channels, not $\mathrm{Ca}^{2+}$ currents.

After providing solid evidence on gluconate inhibition of neonatal seizures, we would like to caution on any attempt to jump on clinic applications before conducting more studies. For example, the working concentration of gluconate is quite high, with an $\mathrm{IC}_{50}$ of NaGluc at 8.6 $\mathrm{mM}$ in inhibiting CLC-3 $\mathrm{Cl}^{-}$channels in neonatal hippocampal neurons in rodents. On the other hand, gluconate is widely used as an additive agent in food and medicine industry. For example, $10 \%$ calcium gluconate was used to treat hyperkalemia and hypocalcemia [53,
54], which is a very high concentration. Another factor to concern is how much gluconate can pass through the blood brain barrier (BBB). While we do not have direct data on this, it is worth to point out that the BBB in neonates may not be as restrictive as that in the adults [55]. Furthermore, some studies also report that BBB may be leakier in the epileptic brains [56, 57]. In fact, as a monocarboxylate, gluconate may cross neonatal BBB through the monocarboxylate transporter [58], but more studies are needed to test the efficacy directly.

In conclusion, our studies have identified a novel anti-epileptic agent gluconate that can inhibit neonatal seizures by blocking CLC-3 $\mathrm{Cl}^{-}$channels. Because gluconate is already used as a food and drug additive for human consumption, our findings may lead to a novel therapy to treat neonatal seizures. On the other hand, since this is only the first study revealing gluconate effect on neonatal seizures in rodents, there are many more studies required to investigate the pre-clinical effects of gluconate on large animals such as non-human primates. Furthermore, before starting any phase I human clinical trial, toxicology studies together with pharmacodynamics and pharmacokinetics studies are necessary to test the safety and dosage of gluconate first in animals. Therefore, this study is a starting point rather than the endpoint toward a potential new clinical therapy.

\section{Materials and methods \\ Animals}

C57BL/6 J mice were purchased from the Jackson Laboratory. The $\mathrm{Clcn}^{-/-}$mice were generated by replacing part of exon 6 and whole exon 7 with a cassette containing the neomycin resistance gene $[18,20,28]$. The majority of experiments were performed at Penn State University. The animal protocol was approved by the Pennsylvania State University IACUC in accordance with the National Institutes of Health Guide for the Care and use of Laboratory Animals. For in vivo experiments on adult mice or neonatal rats, the procedures were approved by the Committee of Animal Use for Research and Education of Fudan University and South China Normal University, respectively, in accordance with the ethical guidelines for animal research. Animal rooms were automatically controlled at $12 \mathrm{~h}$ light/dark cycle, and water and food were available ad libitum.

\section{Cell culture and transfection}

Mouse cortical neurons were prepared from newborn C57BL/6 J mice as previously described [25]. Briefly, the newborn mouse cerebral cortices were dissected out in ice-cold HEPES-buffered saline solution, washed and digested with $0.05 \%$ trypsin-EDTA at $37^{\circ} \mathrm{C}$ for $20 \mathrm{~min}$. After deactivation of trypsin with serum-containing medium, cells were centrifuged, resuspended, and seeded 
on a monolayer of cortical astrocytes at a density of 10,000 cells/cm2 in 24 -well plates. The neuronal culture medium contained MEM (500 ml, Invitrogen), 5\% fetal bovine serum (Atlanta Biologicals), $10 \mathrm{ml} \mathrm{B-27}$ supplement (Invitrogen), $100 \mathrm{mg} \mathrm{NaHCO}_{3}, 2 \mathrm{mM}$ Glutamax (Invitrogen), and 25 units $/ \mathrm{ml}$ penicillin and streptomycin. AraC ( $4 \mu \mathrm{M}$, Sigma) was added to inhibit the excessive proliferation of astrocytes. Cell cultures were maintained in a $5 \% \mathrm{CO}_{2}$-humidified incubator at $37^{\circ} \mathrm{C}$ for 14-21 days.

Human embryonic kidney (HEK) $293 \mathrm{~T}$ cells were maintained in DMEM supplemented with 10\% FBS and 25 units/ml penicillin/streptomycin. PEI kit (molecular weight 25,000, Polysciences, Inc.) was applied for HEK cell transfection. In brief, $1 \mu \mathrm{g}$ DNA was diluted into $50 \mu \mathrm{l}$ of OptiMEM (Invitrogen), then mixed with $4 \mu \mathrm{l}$ of PEI $(1 \mu \mathrm{g} / \mu \mathrm{l})$, incubated for $5 \mathrm{~min}$, and added drop-by-drop to the culture well containing $500 \mu \mathrm{l}$ of medium. After $5 \mathrm{~h}$ incubation, the transfection reagents were washed off by fresh culture medium. Two days after transfection, HEK293T cells were used for electrophysiological study. Rat CLC-3 short transcript fused to eGFP plasmid (pCLC3sGFP) was purchased from Addgene (plasmid \# 52423, Steven Weinman) [29].

\section{Cell viability assay}

A LIVE/DEAD ${ }^{\circ}$ Viability/Cytotoxicity Assay Kit (L3224, Life Technologies) containing ethidium homodimer-1 and calcein-AM was used to examine cell viability. Ethidium homodimer-1 binds to cellular DNA and typically labels dead cells in red fluorescence, while Calcein-AM can be cleaved by esterases in live cells to give strong green fluorescence. After drug treatment, neurons were incubated in bath solution containing $1 \mu \mathrm{M}$ calcein-AM and $4 \mu \mathrm{M}$ ethidium homodimer- 1 at room temperature for $40 \mathrm{~min}$. Cell survival and death rate were measured by quantifying the percentage of green and red fluorescent cells, respectively. For each group, at least 5 fields of each coverslip were imaged for data analysis.

\section{Mouse brain slice preparation}

Brain slices were prepared from C57BL/6 J mice (male and female). Animals were anesthetized with Avertin (tribromoethanol, $250 \mathrm{mg} / \mathrm{kg}$ ) and decapitated. Hippocampal horizontal sections $(300-400 \mu \mathrm{m})$ were prepared by Leica VT1200S vibratome. The neonatal (P6-12) and young adult (P21-33) brain slices were cut in ice-cold artificial cerebral spinal fluid (aCSF) (in $\mathrm{mM}$ ): $125 \mathrm{NaCl}$, $26 \mathrm{NaHCO}_{3}, 10$ glucose, $2.5 \mathrm{KCl}, 2.5 \mathrm{CaCl}_{2}, 1.25$ $\mathrm{NaH}_{2} \mathrm{PO}_{4}$, and $1.3 \mathrm{MgSO}_{4}$, osmolarity 290-300 mOsm, aerated with $95 \% \mathrm{O}_{2} / 5 \% \mathrm{CO}_{2}$. Slices were then transferred to incubation chamber containing normal aCSF saturated with carbogen $\left(95 \% \mathrm{O}_{2} / 5 \% \mathrm{CO}_{2}\right)$ at $33^{\circ} \mathrm{C}$ for
30 min, followed by recovery at room temperature for 1 $\mathrm{h}$ before use. The adult brain slices ( $>2$ months old) were prepared following previously described methods [59], with some additional modifications based on NMDG (N-Methyl-D-glucamine) recovery method. After anesthetized with Avertin, the adult mice was perfused with NMDG cutting solution (in mM): 93 NMDG, $93 \mathrm{HCl}, 2.5 \mathrm{KCl}, 1.25 \mathrm{NaH}_{2} \mathrm{PO}_{4}, 30 \mathrm{NaHCO}_{3}, 20$ HEPES, $12 \mathrm{~N}$-Acetyl-L-cysteine, 15 Glucose, 5 Sodium ascorbate, 2 Thiourea, 3 Sodium pyruvate, $7 \mathrm{MgSO}_{4}, 0.5 \mathrm{CaCl}_{2}$, then the brain was removed and cut in the NMDG cutting solution at room temperature. The brain slices were kept at $32-34{ }^{\circ} \mathrm{C}$ in oxygenated NMDG solution for 10 $15 \mathrm{~min}$. Slices were then transferred to the modified HEPES holding aCSF (in $\mathrm{mM}$ ): $92 \mathrm{NaCl}, 2.5 \mathrm{KCl}, 1.25$ $\mathrm{NaH}_{2} \mathrm{PO}_{4}, 30 \mathrm{NaHCO}_{3}, 20$ HEPES, $12 \mathrm{~N}$-Acetyl-L-cysteine, 15 Glucose, 5 Sodium ascorbate, 2 Thiourea, 3 Sodium pyruvate, $2 \mathrm{MgSO}_{4}, 2 \mathrm{CaCl}_{2}$, for about $0.5-1 \mathrm{~h}$ at room temperature before recording. Individual slices were transferred to a submerged recording chamber where they were continuously perfused $(2-3 \mathrm{ml} / \mathrm{min})$ with normal aCSF saturated by $95 \% \mathrm{O}_{2} / 5 \% \mathrm{CO}_{2}$ at $31-$ $33^{\circ} \mathrm{C}$ (TC-324B, Warner instruments Inc). Slices were visualized with infrared optics using an Olympus microscope equipped with DIC optics.

\section{Electrophysiology \\ Whole-cell recording in cell cultures}

The cultured neurons were placed in the recording chamber with continuous perfusion of the bath solution consisting of (mM): $128 \mathrm{NaCl}, 10$ Glucose, 25 HEPES, 5 $\mathrm{KCl}, 2 \mathrm{CaCl}_{2}, 1 \mathrm{MgSO}_{4}, \mathrm{pH} 7.3$ adjusted with $\mathrm{NaOH}$, and osmolarity $\sim 300 \mathrm{mOsm}$. For recording spontaneous firing under current clamp mode, pipettes were filled with an internal solution containing (in $\mathrm{mM}$ ): $125 \mathrm{~K}$-gluconate, $5 \mathrm{Na}$-phosphocreatine, 5 EGTA, $10 \mathrm{KCl}, 10$ HEPES, 4 Mg-ATP, $0.3 \mathrm{Na}$-GTP, 280-290 mOsm, pH 7.3 adjusted with $\mathrm{KOH}$. Epileptiform activity in cultured neurons was induced either by $10 \mu \mathrm{M}$ cyclothiazide (CTZ) for $24 \mathrm{~h}$, or $1 \mu \mathrm{M} \mathrm{KA}$ for $2 \mathrm{~h}$, or $50 \mu \mathrm{M} 4$-AP for $2 \mathrm{~h}$. The burst activity was defined as previously described [25]. In brief, bursts must contain at least five consecutive action potentials overlaying on top of the large depolarization shift $(\geq 10 \mathrm{mV}$ depolarization and $\geq 300 \mathrm{~ms}$ in duration).

\section{Brain slice recording}

Field potential and cell-attached recordings were performed with glass electrodes (2-4 M $\mathrm{M}$ tip resistance) filled with external solution. The field potential recording electrode was placed into the CA3 pyramidal layer. For current clamp $(\mathrm{I}=0)$ recordings, the amplifier was set at the 100x with a band pass filter of $0.1-5 \mathrm{KHz}$. All recordings were performed at $31-33^{\circ} \mathrm{C}$. The epileptic 
activity was evoked by $\mathrm{Mg}^{2+}$-free aCSF, or addition of $50 \mu \mathrm{M} 4$-AP or $8.5 \mathrm{mM} \mathrm{K}^{+}$in the aCSF. The paroxysmal discharges were defined as in the previous study [33].

For $\mathrm{Cl}^{-}$current recording, $0 \mathrm{Ca}^{2+}$ pipette solution contained either high or normal $\mathrm{Cl}^{-}$were used. High $\mathrm{Cl}^{-}$ pipette solution (mM): $135 \mathrm{CsCl}, 10$ HEPES, 5 EGTA, 5 TEACl, 4 MgATP (pH 7.3 adjusted with $\mathrm{CsOH}, 280-$ $290 \mathrm{mOsm})$; Normal $\mathrm{Cl}^{-}$pipette solution (mM): 125 Cs-Acetate, $10 \mathrm{CsCl}, 10$ HEPES, 5 EGTA, 5 TEA-Cl, 4 MgATP (pH 7.3 adjusted with $\mathrm{CsOH}, 280-290$ mOsm). To isolate $\mathrm{Cl}^{-}$current: (1) Extracellular $\mathrm{Na}^{+}$was replaced by $\mathrm{NMDG}^{+}$and voltage-gated $\mathrm{Na}^{+}$channels were blocked by TTX; (2) $\mathrm{K}^{+}$and $\mathrm{Ca}^{2+}$ were removed from bath solution; (3) $\mathrm{K}^{+}$channels were blocked with $\mathrm{Cs}^{+}$ and tetraethylamonium (TEA) in the pipette solution, and 4-AP in the bath solution; (4) $\mathrm{CdCl}_{2}$ was added into bath solution to block $\mathrm{Ca}^{2+}$ channels; (5) Picrotoxin $(50 \mu \mathrm{M})$ was included to block $\mathrm{GABA}_{\mathrm{A}}$ receptors. Thus, the external solution contained the following (in $\mathrm{mM}$ ): 135 NMDG-Cl, 20 HEPES, 20 Glucose, 5 4-AP and 2 $\mathrm{MgSO}_{4}$, supplemented with $1 \mu \mathrm{M}$ TTX, $200 \mu \mathrm{M} \mathrm{CdCl}$, and $50 \mu \mathrm{M}$ picrotoxin, osmolarity $\sim 300 \mathrm{mOsm}, \mathrm{pH} 7.3-$ 7.4 after aerated with $95 \% \mathrm{O}_{2} / 5 \% \mathrm{CO}_{2}$. Voltage steps from -80 to $+90 \mathrm{mV}(10 \mathrm{mV}$ increments $)$ were applied from holding potential of $0 \mathrm{mV}$ for high $\mathrm{Cl}^{-}$pipette solution $[60,61]$ and voltage steps from -100 to $+30 \mathrm{mV}$ (10 $\mathrm{mV}$ increments) were applied from holding potential of $-60 \mathrm{mV}$ for normal $\mathrm{Cl}^{-}$pipette solution. Data were collected with a MultiClamp 700A amplifier and pCLAMP 10 software (Molecular Devices).

For gramicidin-perforated whole-cell recordings, the $\mathrm{KCl}$ pipette solution was used $(\mathrm{mM}): 135 \mathrm{KCl}, 10$ HEPES, 2 EGTA, 4 MgATP, and $0.3 \mathrm{Na-GTP} \mathrm{(pH} \mathrm{7.3),}$ osmolarity 290-300 mOsm. Pipette tip was first filled with gramicidin-free $\mathrm{KCl}$ internal solution and then back filled with this internal solution containing gramicidin $(40 \mu \mathrm{g} / \mathrm{ml})$. To measure $\mathrm{GABA}_{\mathrm{A}}$ receptor $\left(\mathrm{GABA}_{\mathrm{A}} \mathrm{R}\right)$ reversal potential $\left(E_{\mathrm{GABA}}\right)$, focal pressure ejection of $\mathrm{GABA}_{\mathrm{A}} \mathrm{R}$ agonist isoguvacine $(100 \mu \mathrm{M})$ via a glass pipette controlled by a Picrospitzer (50 ms puff at $10 \mathrm{psi}$ ) was used to activate $\mathrm{GABA}_{\mathrm{A}}$-Rs on CA3 pyramidal neurons with gramicidin-perforated patch $(\mathrm{Ra} \leq 80 \mathrm{M} \Omega$ ) under voltage-clamp at different holding potentials. TTX $(1 \mu \mathrm{M})$, CNQX $(10 \mu \mathrm{M})$ and AP5 $(50 \mu \mathrm{M})$ were added both in the bath and puffer solution to avoid any glutamate currents. The holding potential and peak amplitude were plotted and the $E_{\mathrm{GABA}}$ was determined for each cell.

\section{Power analysis}

Hamming window function was applied before power spectrum analysis. Power was calculated by integrating the root mean square value of the signal in frequency bands from 0.1 to $1000 \mathrm{~Hz}$ in sequential 5-min time windows before, during, and after drug applications. To avoid slice-to-slice and electrode contact variability, power values were normalized to control condition before drug application for each slice, and then averaged across different slices for statistical analysis.

\section{Immunostaining and Western blot Immunostaining}

The neonatal (P12, male and female) and adult (3-4 months, male) mice were anesthetized by Avertin (tribromoethanol, $250 \mathrm{mg} / \mathrm{kg}$, i.p.) and sequentially perfused with ice-cold aCSF and 4\% paraformaldehyde (PFA) in PBS. Brains were collected and postfixed with $4 \%$ PFA overnight at $4{ }^{\circ} \mathrm{C}$. Coronal sections of $40 \mu \mathrm{m}$ thickness were cut by a vibratome (VT1000, Leica, Germany) for immunohistochemistry. For some experiments, brain slices were prepared following the electrophysiology protocol described above, with $200 \mu \mathrm{m}$ thickness for immunostaining and $400 \mu \mathrm{m}$ thickness for Western blot. In general, slices were recovered for $1 \mathrm{~h}$ at room temperature and then randomly divided into two groups. One group of slices were incubated in normal aCSF for $1 \mathrm{~h}$ at $33^{\circ} \mathrm{C}$. Another group of slices were incubated in $0 \mathrm{Mg}^{2+}$ aCSF for $1 \mathrm{~h}$ at $33^{\circ} \mathrm{C}$ to induce epileptiform activity. Slices were then fixed by $4 \%$ PFA overnight at $4{ }^{\circ} \mathrm{C}$. For CLC-3 staining, slices were pretreated with blocking solution (0.3\% Triton-X and 5\% normal donkey and goat serum in $0.1 \mathrm{M} \mathrm{PBS}$ ) for $2 \mathrm{~h}$, and then incubated for $48-72 \mathrm{~h}$ with CLC-3 primary antibody (Rabbit, 1:500, Alomone Labs, ACL-001). Some slices were incubated with rabbit IgG as control. After washing three times in PBS with $0.01 \%$ triton-X, the brain sections were incubated with goat anti rabbit secondary antibodies conjugated to Cy3 (1:500, Jackson ImmunoResearch) for $2 \mathrm{~h}$ at room temperature. The brain sections were mounted on a glass slide with an anti-fading mounting solution (Invitrogen). Fluorescent images were acquired on a confocal microscope system (Olympus FV1000, Japan or Zeiss LSM 880 with airyscan, German). For each slice, at least 2-3 fields of CA3 region were imaged. To quantify CLC-3 fluorescent intensity in CA3 pyramidal layer, confocal images were analyzed using NIH Image J software.

\section{Western blot}

Cell surface biotinylation of mouse brain slices was conducted as published [62]. After euthanization, mouse brains were freshly isolated and sliced into $1 \mathrm{~mm}$ coronal sections. Brain slices were incubated in $1 \mathrm{mg} / \mathrm{ml}$ sulfo-NHS-SS-biotin (ThermoFisher) in pre-chilled oxygenated aCSF on ice for $30 \mathrm{~min}$ and then washed twice with $50 \mathrm{mM}$ glycine and three times with $1 \mathrm{mg} / \mathrm{ml} \mathrm{BSA}$ in pre-chilled oxygenated aCSF. Hippocampus was dissected from slices, extracted and the biotinylated 
proteins purified using NeutrAvidin beads (ThermoFisher) and processed for Western blot with following antibodies: rabbit anti CLC-3 (Rabbit, 1:1000, Alomone, ACL-001), Rabbit anti-Na-K ATPase (1:10,000, Abcam, ab76020). Blots were developed with goat anti-mouse IRDye 680RD and goat anti-rabbit IRDye $800 \mathrm{CW}$ (1:5000, LI-COR) and Odyssey CLx imager (LI-COR) and quantitated using Image Studio (LI-COR).

\section{Electroencephalogram (EEG) recording and analysis}

To test the in vivo anti-epileptic effects of gluconate in neonatal and adult rodents, P8-12 Sprague-Dawley rats or 2-month old male C57BL/6 mice were deeply anesthetized with pentobarbital sodium $(50 \mathrm{mg} / \mathrm{kg}$ for neonatal rat and $100 \mathrm{mg} / \mathrm{kg}$ for adult mice, intraperitoneal injection). Two stainless steel screws (1 $\mathrm{mm}$ in diameter) were inserted into the skull above the cortex as EEG recording electrodes, one ground electrode as well as one reference electrode were located $+1.8 \mathrm{~mm}$ anterior to bregma, $\pm 0.5 \mathrm{~mm}$ lateral to the midline, and $1 \mathrm{~mm}$ below the cortical surface. All electrodes were attached to a micro-connector and fixed onto the skull with dental cement. After surgery, neonatal rats were returned to their mothers and allowed to recover for 2 days prior to subsequent EEG recording. The adult mice were single housed in order to prevent damage of the implanted electrodes and allowed to recover at least 5 days before EEG recording. The baseline of EEG was recorded for $0.5-1 \mathrm{~h}$ to allow the animal to adapt to the environment.

To induce seizure activity, kainic acid (KA, $2 \mathrm{mg} / \mathrm{kg}$ ) was administered intraperitoneally (i.p.) into the neonatal rat. D-gluconic acid sodium salt $(2 \mathrm{~g} / \mathrm{kg})$ or $0.9 \%$ saline was i.p. injected at $10 \mathrm{~min}$ after KA administration. In adult mice, $\mathrm{KA}(10 \mathrm{mg} / \mathrm{kg})$ was i.p. administered to induce seizure burst activity, and D-gluconic acid sodium salt $(2 \mathrm{~g} / \mathrm{kg})$ or $0.9 \%$ saline was i.p. injected at 10 min after KA administration. Epileptiform activity was monitored for $2 \mathrm{~h}$ after KA injection. After the experiment, animals were injected with diazepam to protect the animals from recurrent seizures. The experiments on hypoxia-ischemia induced seizure model included both male and female neonatal rats (Albertsson and Wang, 2015; Zayachkivsky et al., 2015). Rat pups were anesthetized by isofluorane $(5.0 \%$ for induction and $1.0 \%$ for maintenance). The right common carotid artery of neonatal rats was ligated permanently at P5 for ischemia induction. After 3 days recovery, the EEG recording electrodes were implanted in the rat skull at P8. The EEG recording and hypoxia stimulation was performed at P10 (Additional file 1: Figure S6). The electrophysiological signals were amplified (1000x) and filtered $](0-$ $500 \mathrm{~Hz}$ ) with a NeuroLog System (Digitimer Ltd., Hearts, UK) and visualized and stored in a PC through a D-A converter, CED 1401 micro (Cambridge Electronic
Design, Cambridge, UK). The power level of different frequency components in the neonatal EEG signal was examined by power spectrum analysis. Power was calculated in 5-min time windows by root mean square amplitude from 1 to $100 \mathrm{~Hz}$ (EEG band). Seizures were defined as electrographic seizure activity recorded from right hemisphere, only when they were consisted of paroxysmal rhythmic spikes of high amplitude, diffuse frequency of $>8 \mathrm{~Hz}$, lasting $>3 \mathrm{~s}$ [63].

\section{Data analysis}

Data were shown as mean \pm s.e.m. Student's $t$-test (paired or unpaired) and Mann-Whitney test were performed for two-group comparison, and the $x^{2}$ test was used to compare the difference of percentage between two groups. For comparison among multiple groups, one-way ANOVA followed with post hoc tests were used. Statistical significance was set at $P<0.05$.

\section{Additional file}

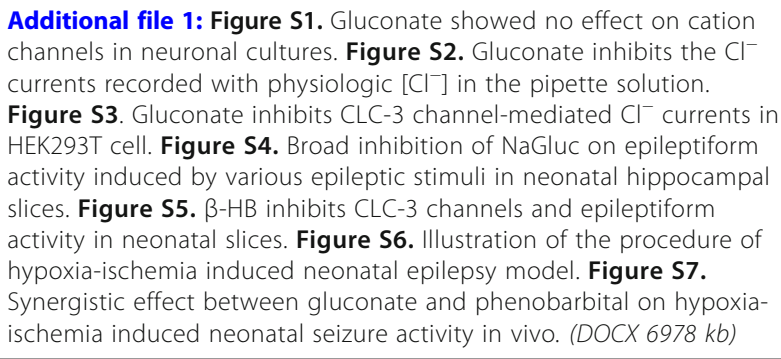

Abbreviations

AEDs: Antiepileptic drugs; Bum: Bumetanide; CTZ: Cyclothiazide; DIDS: 4,4'Diisothiocyanato-2,2'-stilbenedisulfonic acid disodium salt;

EEG: Electroencephalogram; $E_{G A B A}$ : Reversal potential of GABA currents; EthD1: ethidium homodimer-1; GABA: Gamma-Aminobutyric Acid; HI: Hypoxiaischemia; $I_{50}$ : The half maximal inhibitory concentration; KA: Kainic acid; KCC2: $\mathrm{K}^{+}-\mathrm{Cl}^{-}$cotransporter 2; NaGluc: Sodium Gluconate; NKCC1: $\mathrm{Na}^{+}-\mathrm{K}^{+}-\mathrm{Cl}^{-}$ cotransporter 1; NPPB: 5-Nitro-2-(3-phenylpropylamino) benzoic acid;

PCR: Polymerase chain reaction; $\beta$-HB: $\beta$-Hydroxybutyric acid

\section{Acknowledgements}

We would like to thank Dr. Deborah J. Nelson (Professor, University of Chicago) who kindly provided some of the $\mathrm{Clcn}^{-/}$mice for part of our study. We would also like to thank Matthew Wesley Parry at Penn State University for critical reading of the manuscript, and all Chen lab members for rigorous discussion during the progress of this project.

\section{Funding}

This work was supported mainly by grants from National Institutes of Health (AG045656, MH083911) and Charles H. Smith Endowment Fund for Brain Repair from the Pennsylvania State University to G.C. It was also partially supported by NIH MH099851 to B.L., and by grants from the Natural Science Foundation of China $(31771188,31471027)$ to Y.W., and the Recruitment Program of High-end Foreign Experts of the State Administration of Foreign Experts Affairs (GDT20144400031) to G.-Y.W.

Availability of data and materials

All data generated or analyzed during this study are included in this published article and its supplementary information files. 


\section{Authors' contributions}

Z.W. played a major role in designing and performing most of the experiments and analyzing the data, as well as writing the initial draft of the manuscript. G.C. supervised the entire study, designed the experiments with Z.W. and participated in data analysis and revised the manuscript. Q.W.H., G.Y.W., C.L. and G.L.W performed the neonatal in vivo study and some of the adult in vivo study. R.L., S.T.L. and Yun Wang were also involved in the adult in vivo study. Yue Wang, F.P.D., M.Y.F., and B.L. were involved in the Westernblot experiment. Y.T.B. prepared the cell cultures and maintained the mouse lines and did genotyping. All authors have read and approved the final version of the manuscript.

\section{Ethics approva}

The majority of experiments were performed at Penn State University. The animal protocol was approved by the Pennsylvania State University IACUC in accordance with the National Institutes of Health Guide for the Care and use of Laboratory Animals. For in vivo experiments on adult mice or neonatal rats, the procedures were approved by the Committee of Animal Use for Research and Education of Fudan University and South China Normal University, respectively, in accordance with the ethical guidelines for animal research.

\section{Consent for publication}

Not applicable.

\section{Competing interests}

Gong Chen is a founder of NeuExcell Therapeutics Inc.

\section{Publisher's Note}

Springer Nature remains neutral with regard to jurisdictional claims in published maps and institutional affiliations.

\section{Author details}

'Department of Biology, Huck Institutes of Life Sciences, The Pennsylvania State University, University Park, PA 16802, USA. ${ }^{2}$ School of Life Sciences, South China Normal University, Guangzhou 510631, China. ${ }^{3}$ Institutes of Brain Science, Fudan University, Shanghai 200032, China. ${ }^{4}$ Bio-X Institutes, Shanghai Jiao Tong University, 800 Dongchuan Road, Shanghai 200240, China. ${ }^{5}$ Department of Pharmacology, Zhongshan School of Medicine, Sun Yat-sen University, Guangzhou 510080, China. ${ }^{6}$ South China Research Center for Acupuncture-Moxibustion, Medical College of Acupuncture-Moxibustion and Rehabilitation, Guangzhou Univ Chinese Med, Guangzhou 510006, China.

\section{Received: 3 December 2018 Accepted: 17 April 2019}

\section{Published online: 15 May 2019}

\section{References}

1. Jensen FE. Neonatal seizures: an update on mechanisms and management. Clin Perinatol. 2009;36:881-900 vii.

2. Painter MJ, Scher MS, Stein AD, Armatti S, Wang Z, Gardiner JC, Paneth N, Minnigh B, Alvin J. Phenobarbital compared with phenytoin for the treatment of neonatal seizures. N Engl J Med. 1999;341:485-9.

3. Thoresen M, Sabir H. Epilepsy: neonatal seizures still lack safe and effective treatment. Nat Rev Neurol. 2015;11:311-2.

4. Glykys J, Dzhala VI, Kuchibhotla KV, Feng G, Kuner T, Augustine G, Bacskai BJ, Staley KJ. Differences in cortical versus subcortical GABAergic signaling: a candidate mechanism of electroclinical uncoupling of neonatal seizures. Neuron. 2009;63:657-72.

5. Puskarjov M, Kahle KT, Ruusuvuori E, Kaila K. Pharmacotherapeutic targeting of cation-chloride cotransporters in neonatal seizures. Epilepsia. 2014;55: 806-18

6. Bialer M, White HS. Key factors in the discovery and development of new antiepileptic drugs. Nat Rev Drug Discov. 2010;9:68-82.

7. Chen $G$, Trombley $P Q$, van den Pol AN. Excitatory actions of GABA in developing rat hypothalamic neurones. J Physiol. 1996;494(Pt 2):451-64.

8. Ben-Ari Y. Excitatory actions of gaba during development: the nature of the nurture. Nat Rev Neurosci. 2002;3:728-39.

9. Farwell JR, Lee YJ, Hirtz DG, Sulzbacher SI, Ellenberg JH, Nelson KB. Phenobarbital for febrile seizures--effects on intelligence and on seizure recurrence. N Engl J Med. 1990;322:364-9.
10. Loscher W, Puskarjov M, Kaila K. Cation-chloride cotransporters NKCC1 and KCC2 as potential targets for novel antiepileptic and antiepileptogenic treatments. Neuropharmacology. 2013;69:62-74.

11. Kaila K, Price TJ, Payne JA, Puskarjov M, Voipio J. Cation-chloride cotransporters in neuronal development, plasticity and disease. Nat Rev Neurosci. 2014;15:637-54.

12. Dzhala VI, Talos DM, Sdrulla DA, Brumback AC, Mathews GC, Benke TA, Delpire E, Jensen FE, Staley KJ. NKCC1 transporter facilitates seizures in the developing brain. Nat Med. 2005;11:1205-13.

13. Pressler RM, Boylan GB, Marlow N, Blennow M, Chiron C, Cross JH, de Vries LS, Hallberg B, Hellstrom-Westas L, Jullien V, et al. Bumetanide for the treatment of seizures in newborn babies with hypoxic ischaemic encephalopathy (NEMO): an open-label, dose finding, and feasibility phase 1/2 trial. Lancet Neurol. 2015;14:469-77.

14. Wang DD, Kriegstein AR. Blocking early GABA depolarization with bumetanide results in permanent alterations in cortical circuits and sensorimotor gating deficits. Cereb Cortex. 2011;21:574-87.

15. Deidda G, Allegra M, Cerri C, Naskar S, Bony G, Zunino G, Bozzi Y, Caleo M, Cancedda L. Early depolarizing GABA controls critical-period plasticity in the rat visual cortex. Nat Neurosci. 2015;18:87-96.

16. Foldy C, Lee SH, Morgan RJ, Soltesz I. Regulation of fast-spiking basket cell synapses by the chloride channel CIC-2. Nat Neurosci. 2010;13:1047-9.

17. Rinke I, Artmann J, Stein V. CIC-2 voltage-gated channels constitute part of the background conductance and assist chloride extrusion. J Neurosci. 2010; 30:4776-86

18. Wang XQ, Deriy LV, Foss S, Huang P, Lamb FS, Kaetzel MA, Bindokas V, Marks JD, Nelson DJ. CLC-3 channels modulate excitatory synaptic transmission in hippocampal neurons. Neuron. 2006;52:321-33.

19. Glykys J, Dzhala V, Egawa K, Balena T, Saponjian Y, Kuchibhotla KV, Bacskai BJ, Kahle KT, Zeuthen T, Staley KJ. Local impermeant anions establish the neuronal chloride concentration. Science. 2014;343:670-5.

20. Dickerson LW, Bonthius DJ, Schutte BC, Yang B, Barna TJ, Bailey MC, Nehrke K, Williamson RA, Lamb FS. Altered GABAergic function accompanies hippocampal degeneration in mice lacking $\mathrm{ClC}-3$ voltage-gated chloride channels. Brain Res. 2002;958:227-50.

21. Guzman RE, Miranda-Laferte E, Franzen A, Fahlke C. Neuronal ClC-3 splice variants differ in subcellular localizations, but mediate identical transport functions. J Biol Chem. 2015;290:25851-62.

22. Catterall WA. Sodium channels, inherited epilepsy, and antiepileptic drugs. Annu Rev Pharmacol Toxicol. 2014;54:317-38.

23. Rajakulendran S, Hanna MG. The role of calcium channels in epilepsy. Cold Spring Harb Perspect Med. 2016;6:a022723.

24. Kohling R, Wolfart J. Potassium channels in epilepsy. Cold Spring Harb 1178 Perspect Med. 2016;6(5):a022871.

25. Qi J, Wang Y, Jiang M, Warren P, Chen G. Cyclothiazide induces robust epileptiform activity in rat hippocampal neurons both in vitro and in vivo. J Physiol. 2006;571:605-18.

26. Wu Z, Xu Q, Zhang L, Kong D, Ma R, Wang L. Protective effect of resveratrol against kainate-induced temporal lobe epilepsy in rats. Neurochem Res. 2009;34:1393-400.

27. Olsen ML, Schade S, Lyons SA, Amaral MD, Sontheimer H. Expression of voltage-gated chloride channels in human glioma cells. J Neurosci. 2003;23: $5572-82$.

28. Riazanski V, Deriy LV, Shevchenko PD, Le B, Gomez EA, Nelson DJ. Presynaptic CLC-3 determines quantal size of inhibitory transmission in the hippocampus. Nat Neurosci. 2011;14:487-94.

29. Li X, Wang T, Zhao Z, Weinman SA. The CIC-3 chloride channel promotes acidification of lysosomes in CHO-K1 and Huh-7 cells. Am J Physiol Cell Physiol. 2002;282:C1483-91.

30. Lau CG, Zukin RS. NMDA receptor trafficking in synaptic plasticity and neuropsychiatric disorders. Nat Rev Neurosci. 2007:8:413-26.

31. Moody WJ, Bosma MM. Ion channel development, spontaneous activity, and activity-dependent development in nerve and muscle cells. Physiol Rev. 2005:85:883-941.

32. Juge N, Gray JA, Omote H, Miyaji T, Inoue T, Hara C, Uneyama H, Edwards RH, Nicoll RA, Moriyama Y. Metabolic control of vesicular glutamate transport and release. Neuron. 2010;68:99-112.

33. Sada N, Lee S, Katsu T, Otsuki T, Inoue T. Epilepsy treatment. Targeting LDH enzymes with a stiripentol analog to treat epilepsy. Science. 2015;347:1362-7.

34. Slaughter LA, Patel AD, Slaughter UL. Pharmacological treatment of neonatal seizures: a systematic review. J Child Neurol. 2013;28:351-64. 
35. Albertsson AM, Bi D, Duan L, Zhang X, Leavenworth JW, Qiao L, Zhu C, Cardell $\mathrm{S}$, Cantor $\mathrm{H}$, Hagberg $\mathrm{H}$, et al. The immune response after hypoxiaischemia in a mouse model of preterm brain injury. J Neuroinflammation. 2014;11:153.

36. Sampath D, White AM, Raol YH. Characterization of neonatal seizures in an animal model of hypoxic-ischemic encephalopathy. Epilepsia. 2014; 55:985-93.

37. Khoshkhoo S, Vogt D, Sohal VS. Dynamic, cell-type-specific roles for GABAergic interneurons in a mouse model of Optogenetically inducible seizures. Neuron. 2017:93:291-8.

38. Wang Y, Xu C, Xu Z, Ji C, Liang J, Wang Y, Chen B, Wu X, Gao F, Wang S, et al. Depolarized GABAergic signaling in Subicular microcircuits mediates generalized seizure in temporal lobe epilepsy. Neuron. 2017;95:92-105 e105.

39. Tyzio R, Cossart R, Khalilov I, Minlebaev M, Hubner CA, Represa A, Ben-Ari Y, Khazipov R. Maternal oxytocin triggers a transient inhibitory switch in GABA signaling in the fetal brain during delivery. Science. 2006;314:1788-92.

40. Kilb W, Sinning A, Luhmann HJ. Model-specific effects of bumetanide on epileptiform activity in the in-vitro intact hippocampus of the newborn mouse. Neuropharmacology. 2007;53:524-33.

41. Chen TT, Klassen TL, Goldman AM, Marini C, Guerrini R, Noebels JL. Novel brain expression of $\mathrm{ClC}-1$ chloride channels and enrichment of CLCN1 variants in epilepsy. Neurology. 2013;80:1078-85.

42. Saint-Martin C, Gauvain G, Teodorescu G, Gourfinkel-An I, Fedirko E, Weber YG, Maljevic S, Ernst JP, Garcia-Olivares J, Fahlke C, et al. Two novel CLCN2 mutations accelerating chloride channel deactivation are associated with idiopathic generalized epilepsy. Hum Mutat. 2009;30:397-405.

43. Kleefuss-Lie A, Friedl W, Cichon S, Haug K, Warnstedt M, Alekov A, Sander T, Ramirez A, Poser B, Maljevic S, et al. CLCN2 variants in idiopathic generalized epilepsy. Nat Genet. 2009;41:954-5.

44. Niemeyer MI, Cid LP, Sepulveda FV, Blanz J, Auberson M, Jentsch TJ. No evidence for a role of CLCN2 variants in idiopathic generalized epilepsy. Nat Genet. 2010:42:3.

45. Duran C, Thompson CH, Xiao Q, Hartzell HC. Chloride channels: often enigmatic, rarely predictable. Annu Rev Physiol. 2010;72:95-121.

46. Verkman AS, Galietta LJ. Chloride channels as drug targets. Nat Rev Drug Discov. 2009;8:153-71.

47. Farmer LM, Le BN, Nelson DJ. CLC-3 chloride channels moderate long-term potentiation at Schaffer collateral-CA1 synapses. J Physiol. 2013:591:1001-15.

48. Fritschy JM, Panzanelli P. GABAA receptors and plasticity of inhibitory neurotransmission in the central nervous system. Eur J Neurosci. 2014;39: 1845-65.

49. Habela CW, Olsen ML, Sontheimer H. ClC3 is a critical regulator of the cell cycle in normal and malignant glial cells. J Neurosci. 2008;28:9205-17.

50. Blaesse P, Airaksinen MS, Rivera C, Kaila K. Cation-chloride cotransporters and neuronal function. Neuron. 2009;61:820-38.

51. Belluzzo M, Monti F, Pizzolato G. A case of hypocalcemia-related epilepsia partialis continua. Seizure. 2011;20:720-2.

52. Sawyer DT. Metal-Gluconate Complexes. Chem Rev. 1964;64:633-\&.

53. Zhao Y, Linden J, Welch L, St Pierre P, Graves M, Garrity D, Ducharme P, Bailey JA, Greene M, Vauthrin M, Weinstein R. Prophylactic infusion of calcium gluconate to prevent a symptomatic fallin plasma ionized calcium during therapeutic plasma exchange: a comparison of two methods. J Clin Apher. 2018;33(5):600-603.

54. Phillips DR, Ahmad KI, Waller SJ, Meisner P, Karet FE. A serum potassium level above $10 \mathrm{mmol} / \mathrm{l}$ in a patient predisposed to hypokalemia. Nat Clin Pract Nephrol. 2006;2:340-6 quiz 347.

55. Ek CJ, Dziegielewska KM, Habgood MD, Saunders NR. Barriers in the developing brain and Neurotoxicology. Neurotoxicology. 2012;33:586-604.

56. Marchi N, Granata T, Ghosh C, Janigro D. Blood-brain barrier dysfunction and epilepsy: pathophysiologic role and therapeutic approaches. Epilepsia. 2012;53:1877-86.

57. van Vliet EA, Aronica E, Gorter JA. Blood-brain barrier dysfunction, seizures and epilepsy. Semin Cell Dev Biol. 2015;38:26-34.

58. Vijay $\mathrm{N}$, Morris ME. Role of monocarboxylate transporters in drug delivery to the brain. Curr Pharm Des. 2014;20:1487-98.

59. Ting JT, Daigle TL, Chen Q, Feng G. Acute brain slice methods for adult and aging animals: application of targeted patch clamp analysis and optogenetics. Methods Mol Biol. 2014;1183:221-42.

60. Billig GM, Pal B, Fidzinski P, Jentsch TJ. Ca2+-activated cl- currents are dispensable for olfaction. Nat Neurosci. 2011;14:763-9.
61. Huang WC, Xiao S, Huang F, Harfe BD, Jan YN, Jan LY. Calcium-activated chloride channels (CaCCs) regulate action potential and synaptic response in hippocampal neurons. Neuron. 2012;74:179-92.

62. Ren Z, Pribiag H, Jefferson SJ, Shorey M, Fuchs T, Stellwagen D, Luscher B. Bidirectional homeostatic regulation of a depression-related brain state by gamma-aminobutyric Acidergic deficits and ketamine treatment. Biol Psychiatry. 2016;80:457-68.

63. Cleary RT, Sun H, Huynh T, Manning SM, Li Y, Rotenberg A, Talos DM, Kahle KT, Jackson M, Rakhade SN, et al. Bumetanide enhances phenobarbital efficacy in a rat model of hypoxic neonatal seizures. PLoS One. 2013;8: e57148.

\section{Ready to submit your research? Choose BMC and benefit from:}

- fast, convenient online submission

- thorough peer review by experienced researchers in your field

- rapid publication on acceptance

- support for research data, including large and complex data types

- gold Open Access which fosters wider collaboration and increased citations

- maximum visibility for your research: over $100 \mathrm{M}$ website views per year

At BMC, research is always in progress.

Learn more biomedcentral.com/submissions 